\title{
Reconstruction and analysis of a genome-scale metabolic model for Scheffersomyces stipitis
}

Balaji Balagurunathan', Sudhakar Jonnalagadda', Lily $\operatorname{Tan}^{1}$ and Rajagopalan Srinivasan ${ }^{1,2^{*}}$

\begin{abstract}
Background: Fermentation of xylose, the major component in hemicellulose, is essential for economic conversion of lignocellulosic biomass to fuels and chemicals. The yeast Scheffersomyces stipitis (formerly known as Pichia stipitis) has the highest known native capacity for xylose fermentation and possesses several genes for lignocellulose bioconversion in its genome. Understanding the metabolism of this yeast at a global scale, by reconstructing the genome scale metabolic model, is essential for manipulating its metabolic capabilities and for successful transfer of its capabilities to other industrial microbes.

Results: We present a genome-scale metabolic model for Scheffersomyces stipitis, a native xylose utilizing yeast. The model was reconstructed based on genome sequence annotation, detailed experimental investigation and known yeast physiology. Macromolecular composition of Scheffersomyces stipitis biomass was estimated experimentally and its ability to grow on different carbon, nitrogen, sulphur and phosphorus sources was determined by phenotype microarrays. The compartmentalized model, developed based on an iterative procedure, accounted for 814 genes, 1371 reactions, and 971 metabolites. In silico computed growth rates were compared with high-throughput phenotyping data and the model could predict the qualitative outcomes in $74 \%$ of substrates investigated. Model simulations were used to identify the biosynthetic requirements for anaerobic growth of Scheffersomyces stipitis on glucose and the results were validated with published literature. The bottlenecks in Scheffersomyces stipitis metabolic network for xylose uptake and nucleotide cofactor recycling were identified by in silico flux variability analysis. The scope of the model in enhancing the mechanistic understanding of microbial metabolism is demonstrated by identifying a mechanism for mitochondrial respiration and oxidative phosphorylation.

Conclusion: The genome-scale metabolic model developed for Scheffersomyces stipitis successfully predicted substrate utilization and anaerobic growth requirements. Useful insights were drawn on xylose metabolism, cofactor recycling and mechanism of mitochondrial respiration from model simulations. These insights can be applied for efficient xylose utilization and cofactor recycling in other industrial microorganisms. The developed model forms a basis for rational analysis and design of Scheffersomyces stipitis metabolic network for the production of fuels and chemicals from lignocellulosic biomass.
\end{abstract}

Keywords: Genome scale metabolic models, Scheffersomyces stipitis, Metabolic flux analysis, Xylose utilization, Anaerobic growth

\section{Background}

Scheffersomyces stipitis (S. stipitis), formerly known as Pichia stipitis [1], is a hemiascomycetous yeast, closely related to several yeast endosymbionts of passalid beetles that inhabit and decay white-rotted hardwood $[2,3]$. It

\footnotetext{
* Correspondence: chergs@nus.edu.sg

${ }^{1}$ Institute of Chemical and Engineering Sciences, Agency for Science, Technology and Research, 1, Pesek Road, Jurong Island, Singapore 627833, Singapore

Full list of author information is available at the end of the article
}

has the highest native capacity for xylose fermentation of any known microbe $[4,5]$. Fed batch cultures of $S$. stipitis produce around $47 \mathrm{~g} / \mathrm{l}$ of ethanol with yields of $0.36 \mathrm{~g} / \mathrm{g}$ xylose at $30^{\circ} \mathrm{C}$ [4]. In addition to xylose, S. stipitis has the capability to ferment sugars from hydrolysates with yields equivalent to $80 \%$ of theoretical yield [6-8]. Auxotrophic strains have been created and methods for high efficiency transformation have been developed for S. stipitis $[9,10]$. Genetic tools based on a loxP/Cre recombination system have been developed for functional genomics and
C Biomed Central

(C) 2012 Balagurunathan et al; BioMed Central Ltd. This is an Open Access article distributed under the terms of the Creative Commons Attribution License (http://creativecommons.org/licenses/by/2.0), which permits unrestricted use, distribution, and reproduction in any medium, provided the original work is properly cited. 
metabolic engineering of this yeast [11]. The availability of genetic tools and capability for fermentation of hydrolysates has made $S$. stipitis an attractive microorganism for bioconversion of lignocellulose to fuels and chemicals. S. stipitis has already been successfully engineered to produce lactic acid and xylitol $[12,13]$. However, S. stipitis suffers from some drawbacks like lower fermentation rates, lower tolerance to ethanol and absence of anaerobic growth $[5,14,15]$.

As a parallel approach, xylose utilization pathway from $S$. stipitis has been used to engineer xylose metabolism in Saccharomyces cerevisiae. Successive cycles of metabolic engineering have improved xylose utilization in recombinant $S$. cerevisiae $[16,17]$. However, the ethanol productivity from xylose is still low. This has been attributed to: low substrate affinity of recombinant enzymes [18]; cofactor imbalance in the XR-XDH reactions $[19,20]$; low xylose transport capacity $[21,22]$; and failure to recognize xylose as a fermentable carbon source [23,24]. The holistic analysis of metabolism in S. stipitis could provide useful insights to identify shortcomings in S. stipitis and S. cerevisiae metabolic networks.

The complete genome of $S$. stipitis has been sequenced [25]. The functional annotation of the genome sequence showed numerous genes for lignocellulose bioconversion and systematic analysis of the genome sequence annotation is necessary to obtain useful insights. Genome scale metabolic models, which represent the link between the genotype and phenotype of the organism, can be reconstructed based on the genome sequence annotation and relevant biochemical and physiological information. These models have the ability to provide a holistic view of the metabolism of an organism. Once experimentally validated, these models can be used to characterize the metabolic resource allocation, generate experimentally testable predictions of cellular phenotypes, elucidate metabolic network evolution scenarios, design experiments that most effectively reveal the genotype-phenotype relationships, and design engineered microorganisms with desired properties like overproduction of commercially valuable chemicals [26-30]. Due to the genome wide-scale, these models enable systematic assessment of how perturbations in the metabolic network affect the organism as a whole which may not be possible by analyzing a set of enzymes or isolated pathways.

We have reported a framework for reconstruction of genome scale metabolic model of S. stipitis [31]. In this study, a genome scale metabolic model has been developed for S. stipitis based on the proposed framework and a recently published protocol [32]. Experimental procedure for the estimation of macromolecular composition of S. stipitis was standardized and used to obtain the biomass composition. Growth and non-growth associated maintenance energy requirements were also estimated from experimental data. The model was refined and validated based on the ability of S. stipitis to grow on different carbon, nitrogen, sulphur and phosphorus sources. In silico analysis of the model was used to identify biosynthetic requirements for anaerobic growth of S. stipitis in glucose and to analyze xylose utilization capability in S. stipitis. Model simulations were carried out to obtain insights on the recycling of nucleotide cofactors and mechanisms involved in mitochondrial respiration and oxidative phosphorylation.

\section{Results}

Reconstruction of the genome scale metabolic model for Scheffersomyces stipitis

An initial metabolic reconstruction for S. stipitis was developed based on the protocol outlined in the methods section (Figure 1). Biomass macromolecular composition was experimentally determined. The constituents of biomass and the fractional contribution of these constituents to overall cellular biomass are summarized in Table 1 . The growth and non-growth associated maintenance coefficient (GAM and NGAM) was estimated from growth rate and substrate uptake rate data. The details of the estimation are provided in the supplementary information (Additional File 1). The initial metabolic network consisted of 1167 reactions and this network was expanded to 1371 reactions based on high-throughput Biolog phenotyping data and metabolic gap analysis.

\section{Characteristics of the reconstructed network}

The characteristics of the reconstructed S. stipitis metabolic network are detailed in Figure 2. The complete reconstruction accounted for 814 open reading frames (ORFs) and consisted of 1370 reactions and 644 unique metabolites (Figure 2A). The details of the list of genes, reactions, metabolites and the GPR associations in the reconstruction are available as supplementary information (Additional File 2). The functional classification of the ORFs included in the reconstruction is summarized in Figure 2B. The reactions in the model were assigned to 57 different subsystems, organized into 8 groups. The number of non-gene associated reactions in each of these groups is shown in Figure 2C. The distribution of enzyme classes in the model is shown in Figure 2D.

The basic capabilities of the in silico model to predict quantitatively the aerobic growth on glucose was determined. A growth demand function was formulated based on the estimated biomass composition detailing the required metabolites in the appropriate ratios. This demand function was used as the objective function for flux balance analysis. The number of genes and reactions essential for the production of biomass from a glucose based minimal media was computed. The distribution of essential reactions and essential genes among pathway 


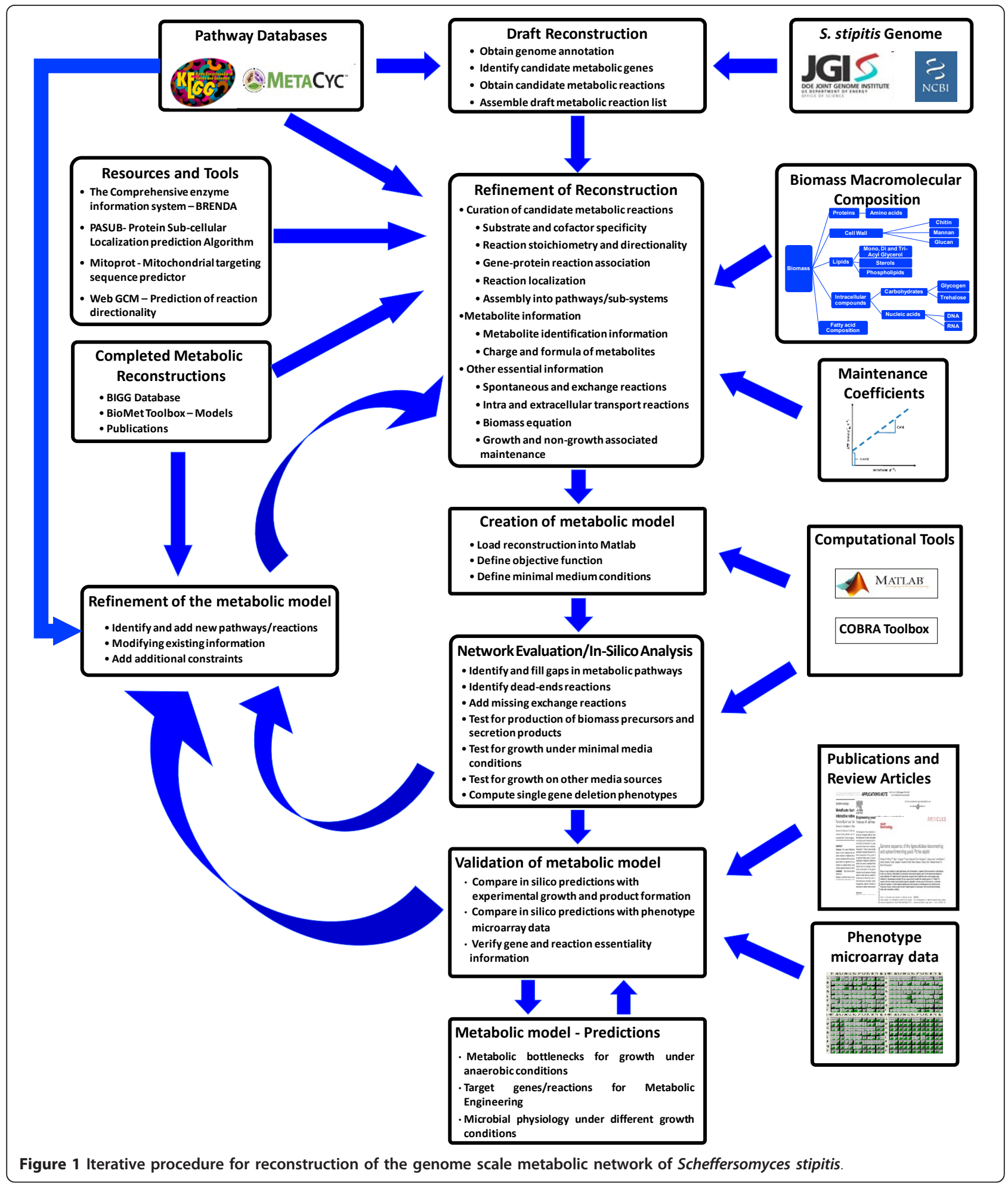

groups is shown in Figure 3A and Figure 3B. The highest number of essential genes and reaction where associated with amino acid metabolism followed by nucleotide and lipid metabolism. The list of essential reactions is provided in supplementary information (Additional File 3). Capability to produce various amino acids from glucose was analyzed using the genome scale metabolic model and compared with that obtained with $S$. cerevisiae 
Table 1 Macromolecular composition of S. stipitis Biomass

\begin{tabular}{llll}
\hline Biomass Composition of Scheffersomyces stipitis & \\
\hline Metabolite & $\begin{array}{l}\text { mmol/ } \\
\text { gDCW }\end{array}$ & Metabolite & $\begin{array}{l}\text { mmol/ } \\
\text { gDCW }\end{array}$ \\
\hline Amino Acids & & DNA & \\
\hline Aspartic Acid & 0.1566 & dAMP & 0.0112 \\
\hline Threonine & 0.1809 & dTMP & 0.0112 \\
\hline Serine & 0.2330 & dGMP & 0.0084 \\
\hline Glutamic Acid & 0.3190 & dCMP & 0.0084 \\
\hline Glycine & 0.4724 & RNA & \\
\hline Alanine & 0.4735 & AMP & 0.0444 \\
\hline Cystine & 0.0511 & UMP & 0.0522 \\
\hline Valine & 0.2201 & GMP & 0.0361 \\
\hline Methionine & 0.0559 & CMP & 0.0388 \\
\hline Iso-Leucine & 0.1454 & Lipids & \\
\hline Leucine & 0.2451 & Sterol (ergosterol) & 0.0560 \\
\hline Tyrosine & 0.0741 & Phospholipids & 0.07156 \\
\hline Phenylalanine & 0.1127 & Phosphatidyllnositol & 0.0015 \\
\hline Histidine & 0.1005 & Phosphatidylethanolamine & 0.0041 \\
\hline Lysine & 0.2624 & Phosphatidylcholine & 0.0255 \\
\hline Arginine & 0.1821 & Carbohydrates & \\
\hline Tryptophan & 0.0248 & Glycogen & 0.2714 \\
\hline Proline & 0.1592 & Trehalose & 0.0760 \\
\hline Asparagine & 0.1511 & Glucan & Mannan \\
\hline Glutamine & 0.1817 & Chitin & \\
\hline & & & 0.6107 \\
\hline & & & \\
\hline
\end{tabular}

[33]. The theoretical yield of various amino acids on carbon mole basis is shown in Figure 3C. The yields obtained were comparable between the two yeasts, indicating the similarity in the biosynthetic networks for amino acid synthesis.

\section{Analysis of high-throughput substrate utilization}

The in silico computations were compared with the high throughput phenotyping data from Biolog's Phenotype microarray technology [34] (Figure 4). 339 out of the 379 substrates tested (190 for carbon, 95 for Nitrogen, 59 for Phosphorus and 35 for Sulphur sources) were identified as data with sufficient confidence (Confidence of the data was estimated as described in the methods section) and were analyzed for consistency using the $S$. stipitis model. The list of substrates, confidence levels of data and model refinements are described in supplementary information (Additional File 4). Growth on substrates was simulated by fixing its specific uptake rate at $5 \mathrm{mmol} / \mathrm{gDCW} / \mathrm{h}$ under aerobic conditions based on minimal media (Methods Section). The initial metabolic network reconstruction could predict qualitatively the outcome of Biolog data with 56\% accuracy
(189 in 339), but after network expansion and metabolic gap analysis, overall prediction efficiency was considerably improved to $74 \%$ (252 in 339) (Figure 4A). However, 14 disagreements ( 9 for carbon and 5 for nitrogen) were observed (Figure 4B); of these 5 cases were compared with experimental growth data available in literature for S. stipitis or related yeasts for corresponding substrates (Figure 4C).

Biolog phenotyping results indicated that capric acid and caproic acid cannot by utilized by $S$. stipitis as a sole carbon source, but the model predicted growth. However, it has been observed that capric, caproic and other fatty acids were known to inhibit the growth of S. stipitis [35,36] and other yeasts [37]. Since the inhibition mechanisms are not incorporated in the metabolic model, the in silico computations predicted growth on these substrates. In the case of nitrogen source utilization, Biolog phenotyping results and experimental data reported by $[38,39]$ indicated growth on lysine as a sole nitrogen source. However, the in silico predictions did not predict growth as the pathway enzymes involved in metabolism of lysine has not been identified in S. stipitis genome. The in silico growth predictions for Biolog substrates evaluated as low confidence data were also compared with data available in literature for corresponding substrates. Experimental data was available from literature $[38,39]$ for 5 out of 40 low-confidence cases and the model could correctly predict the utilization of these substrates with $80 \%$ accuracy (4 cases)(Figure 4D). Incorrect prediction for glucuronic acid was due to the lack of homologs for pathway enzymes. The examples of lysine and glucuronic acid utilization illustrate the capability of the model to pinpoint potential gaps in the understanding of metabolism and to guide experimental design.

\section{Metabolic requirements for anaerobic growth of Scheffersomyces stipitis}

One drawback for using S. stipitis in industrial fermentation is its inability to grow under anaerobic conditions. The model developed was used to analyze the requirements for anaerobic growth. The model was simulated for anaerobic growth on a glucose based minimal media by reducing the oxygen uptake rate to zero, with an unconstrained uptake of sterols and unsaturated fatty acids (which have a known biosynthetic requirement for oxygen). No growth was predicted by the model simulations under these conditions. Growth under anaerobic conditions is a complex process. Several requirements need to be met for growth including biosynthetic requirements for oxygen, energy requirements, redox balance requirements and regulatory requirements.

While performing the model simulations, even though sterol and unsaturated fatty acids were added there 


A
\begin{tabular}{|l|r|}
\hline Genome Characteristics & $15.4 \mathrm{Mb}$ \\
\hline Genome Size & 5841 \\
\hline Total coding sequences & \\
\hline & \\
\hline In Silico Model Characteristics & 814 \\
\hline Metabolic genes & $14.4 \%$ \\
\hline Percentage of genome & 1370 \\
\hline Metabolic reactions & 872 \\
\hline \multicolumn{1}{|c|}{ Gene associated } & 498 \\
\hline \multicolumn{1}{|c|}{ Non- gene associated } & 211 \\
\hline Exchange reactions & $971(644)$ \\
\hline Metabolites(unique) & $3(\mathrm{c}, \mathrm{m}, \mathrm{e})$ \\
\hline Compartments & 57 \\
\hline Subsystems & \\
\hline
\end{tabular}

\section{B}
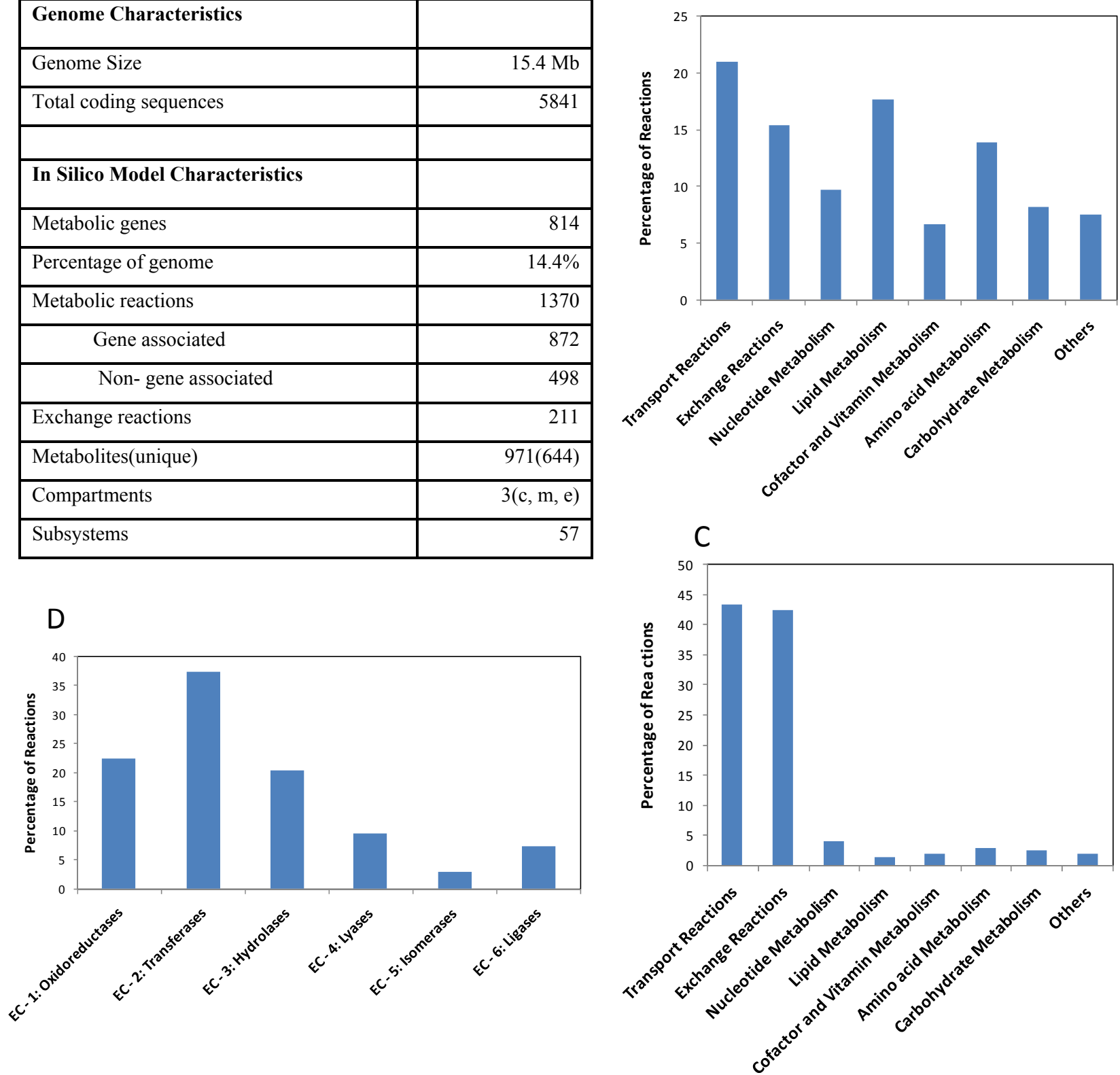

Figure 2 Characteristics of the genome scale metabolic network. A) Statistics. B) Functional classification of metabolic reactions in the model. C) Functional classification of the non-gene associated metabolic reactions in the model. D) Functional classification of enzyme classes in the model.

could be other metabolites or biomass constituents in yeasts that requires oxygen for their biosynthesis. To identify the biosynthetic requirements for anaerobic growth, reaction insertion analysis was performed on the model using the reference metabolic database KEGG [40]. An initial set of metabolic reactions (802 reactions) were compiled from the KEGG database that is made up of only metabolites present in the model. These reactions were then inserted one at a time to determine their effect on growth under anaerobic conditions. Reactions already present in the model were ignored. Single reaction additions that resulted in a positive biomass flux were identified. The list of reactions leading to a positive biomass flux is summarized in Table 2. There were 28 such reactions, 12 of these reactions directly resulted in oxygen production. 10 reactions resulted in oxygen production through the formation of $\mathrm{H}_{2} \mathrm{O}_{2}$ (either directly or through glutathione or pyridoxine) 


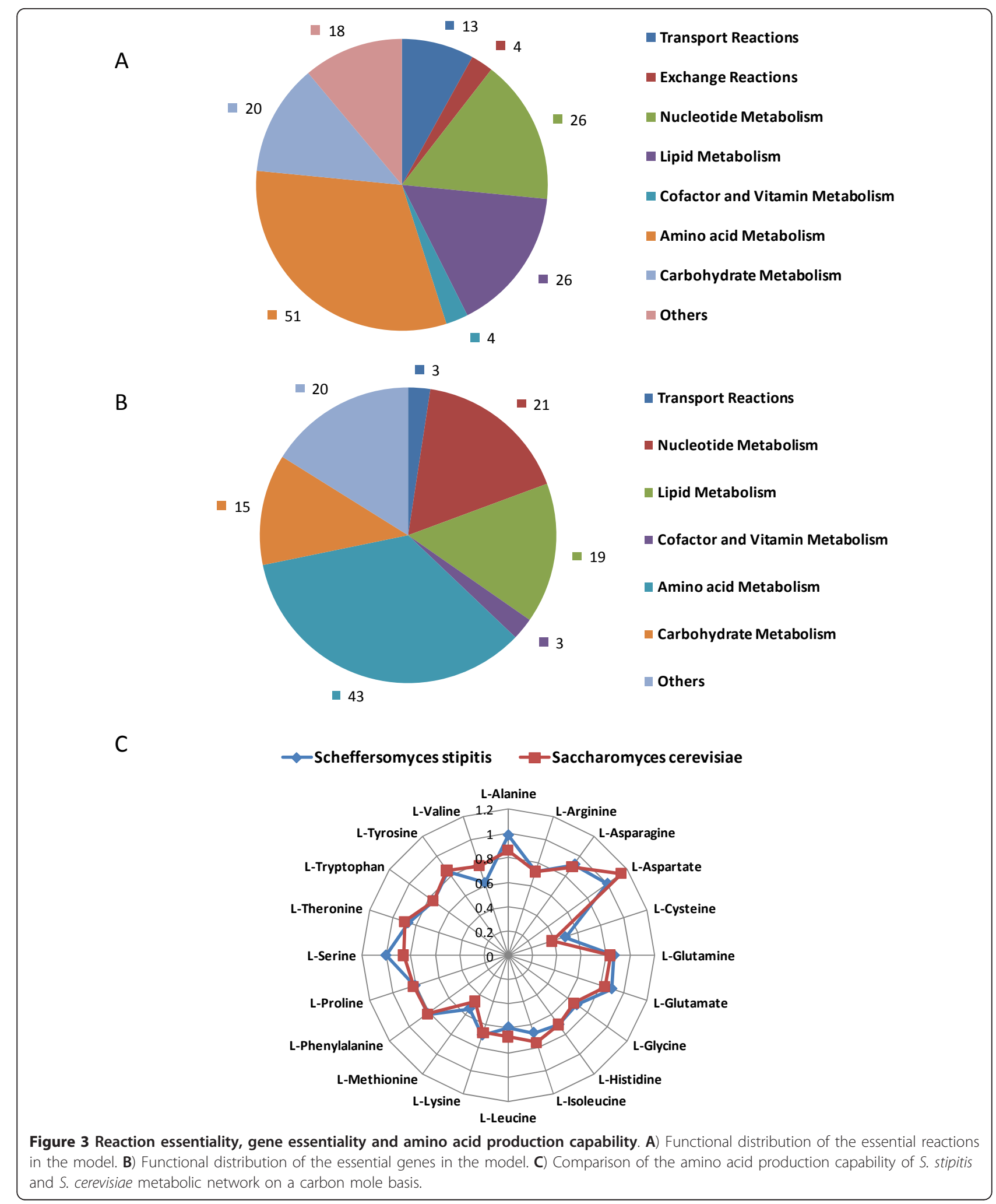

and the remaining 6 reactions were selected for further analysis. Four of these reactions involve phospholipids and the stoichiometry of these reactions in the KEGG database is different from the way lipid metabolism reactions are represented in the metabolic model. The remaining two reactions convert dihydroorotate to 


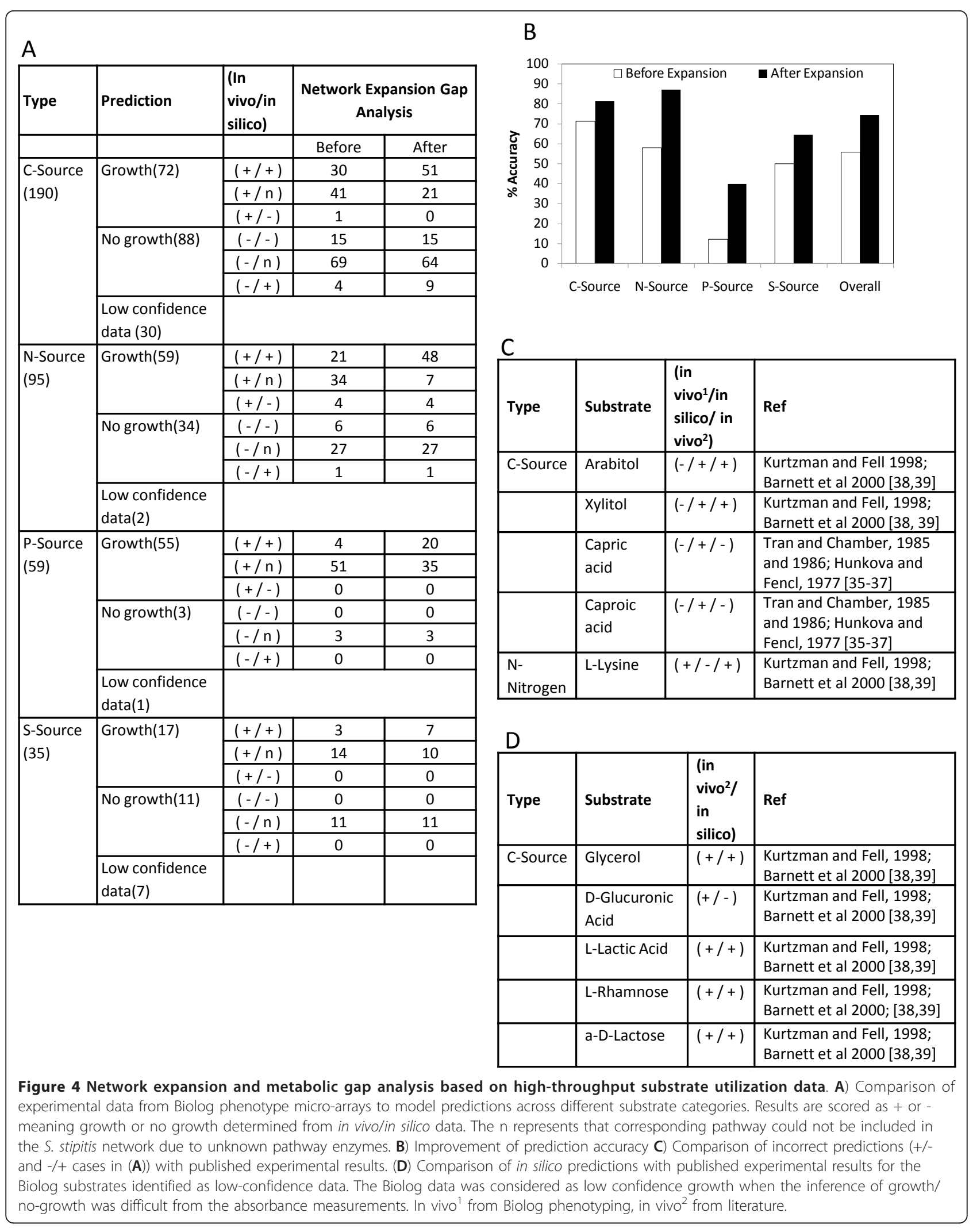


Table 2 List of reactions that lead to anaerobic growth on glucose identified by single reaction insertion analysis

\begin{tabular}{|c|c|c|c|c|}
\hline S.NO & R Numbers & Reaction Formula & Biomass Flux & Reaction Flux \\
\hline 1 & R00090* & $\mathrm{h} 2 \mathrm{O} 2[\mathrm{c}]+\mathrm{h}[\mathrm{c}]+\operatorname{nadh}[\mathrm{c}]<=>2 \mathrm{~h} 2 \mathrm{o}[\mathrm{c}]+\operatorname{nad}[\mathrm{c}]$ & 0.4049 & -20.0000 \\
\hline 2 & R00094* & $\operatorname{nad}[c]+2 \operatorname{gthrd}[c]<=>$ h[c] + nadh $[c]+\operatorname{gthox}[c]$ & 0.4049 & 20.0000 \\
\hline 3 & R00113* & $\mathrm{h} 2 \mathrm{o} 2[\mathrm{c}]+\mathrm{h}[\mathrm{c}]+\operatorname{nadph}[\mathrm{c}]<=>2 \mathrm{~h} 2 \mathrm{o}[\mathrm{c}]+\operatorname{nadp}[\mathrm{c}]$ & 0.4491 & -20.0000 \\
\hline 4 & R00115* & $\operatorname{nadp}[\mathrm{c}]+2 \operatorname{gthrd}[\mathrm{c}]<=>\mathrm{h}[\mathrm{c}]+\operatorname{nadph}[\mathrm{c}]+\operatorname{gthox}[\mathrm{c}]$ & 0.4491 & 20.0000 \\
\hline 5 & $\mathrm{R} 00211^{\$}$ & $\mathrm{O} 2[\mathrm{c}]+\operatorname{pyr}[\mathrm{c}]+\mathrm{coa}[\mathrm{c}]<=>\mathrm{h} 2 \mathrm{o} 2[\mathrm{c}]+\mathrm{accoa}[\mathrm{c}]+\mathrm{co} 2[\mathrm{c}]$ & 0.2279 & -2.6049 \\
\hline 6 & R00319 & $\mathrm{o} 2[\mathrm{c}]+\mathrm{lac}-\mathrm{L}[\mathrm{c}]<=>\mathrm{h} 2 \mathrm{o}[\mathrm{c}]+\mathrm{ac}[\mathrm{c}]+\mathrm{co} 2[\mathrm{c}]$ & 0.6300 & -20.0000 \\
\hline 7 & R00360 & $\mathrm{o} 2[\mathrm{c}]+\mathrm{mal}-\mathrm{L}[\mathrm{c}]<=>\mathrm{oaa}[\mathrm{c}]+\mathrm{h} 2 \mathrm{o} 2[\mathrm{c}]$ & 0.2079 & -0.1820 \\
\hline 8 & R00475 \$ & $\mathrm{O} 2[\mathrm{c}]+$ glyclt $[\mathrm{c}]<=>$ glx $[\mathrm{c}]+\mathrm{h} 2 \mathrm{O} 2[\mathrm{c}]$ & 0.2038 & -0.0225 \\
\hline 9 & R00481 & asp-L[c] $+02[c]<=>$ h2o2[c] $+\operatorname{iasp}[c]$ & 0.2055 & -0.1579 \\
\hline 10 & R00500* & 2 gthrd $[c]<=>$ gthox $[c]$ & 0.6061 & 20.0000 \\
\hline 11 & R00533\$ & $\mathrm{h} 2 \mathrm{o}[\mathrm{c}]+\mathrm{o} 2[\mathrm{c}]+\mathrm{so} 3[\mathrm{c}]<=>\mathrm{h} 2 \mathrm{o} 2[\mathrm{c}]+\mathrm{so} 4[\mathrm{c}]$ & 0.2133 & -0.2130 \\
\hline 12 & R00846 & $\mathrm{O} 2[\mathrm{c}]+\mathrm{glyc} 3 \mathrm{p}[\mathrm{c}]<=>\mathrm{h} 2 \mathrm{o} 2[\mathrm{c}]+$ dhap $[\mathrm{c}]$ & 0.2075 & -0.1817 \\
\hline 13 & R01712* & $\operatorname{pyr}[c]+\operatorname{pydam}[c]<=>$ ala-L[c] $+\operatorname{pydx}[c]$ & 0.4073 & 20.0000 \\
\hline 14 & R01713* & $\operatorname{oaa}[c]+\operatorname{pydam}[c]<=>$ asp-L[c] + pydx $[c]$ & 0.4049 & 20.0000 \\
\hline 15 & $\mathrm{R} 01769^{\$}$ & $\mathrm{~h} 2 \mathrm{o}[\mathrm{c}]+\mathrm{o} 2[\mathrm{c}]+\mathrm{hxan}[\mathrm{c}]<=>\mathrm{h} 2 \mathrm{o} 2[\mathrm{c}]+\operatorname{xan}[\mathrm{c}]$ & 0.2079 & -0.1820 \\
\hline 16 & R01797" & $\mathrm{h} 2 \mathrm{o}[\mathrm{c}]+\mathrm{cdpdag}[\mathrm{c}]<=>\mathrm{pa}[\mathrm{c}]+\mathrm{cmp}[\mathrm{c}]$ & 17.8571 & -7.4901 \\
\hline 17 & R01799\# & $\mathrm{pa}[\mathrm{c}]+\mathrm{ctp}[\mathrm{c}]<=>\operatorname{ppi}[\mathrm{c}]+\operatorname{cdpdag}[\mathrm{c}]$ & 17.8571 & 7.5572 \\
\hline 18 & R01800 & ser-L[c] + cdpdag[c] $<=>\operatorname{cmp}[c]+p s[c]$ & 0.2073 & -0.0005 \\
\hline 19 & R01866" & nadp[c] + dhor-S[c] $<=>$ h[c] + nadph $[c]+\operatorname{orot}[c]$ & 0.2062 & 0.0228 \\
\hline 20 & R01869 & $\operatorname{nad}[\mathrm{c}]+\operatorname{dhor}-\mathrm{S}[\mathrm{c}]<=>\mathrm{h}[\mathrm{c}]+\operatorname{nadh}[\mathrm{c}]+\operatorname{orot}[\mathrm{c}]$ & 0.2056 & 0.0227 \\
\hline 21 & R01879 & $\operatorname{akg}[c]+02[c]+\operatorname{duri}[c]<=>\operatorname{co} 2[c]+\operatorname{succ}[c]+$ uri $[c]$ & 0.3581 & -12.8155 \\
\hline 22 & R01909* & $\operatorname{atp}[c]+\operatorname{pydxn}[c]<=>\operatorname{adp}[c]+\operatorname{pdx} 5 p[c]$ & 0.3147 & -20.0000 \\
\hline 23 & R01911* & pi $[c]+\operatorname{pydxn}[c]<=>$ h2o[c] + pdx5p[c] & 0.2312 & -1.0484 \\
\hline 24 & $\mathrm{R} 02107^{\$}$ & $\mathrm{~h} 2 \mathrm{o}[\mathrm{c}]+\mathrm{o} 2[\mathrm{c}]+\operatorname{xan}[\mathrm{c}]<=>\mathrm{h} 2 \mathrm{o} 2[\mathrm{c}]+$ urate$[\mathrm{c}]$ & 0.2079 & -0.1820 \\
\hline 25 & R05717* & $\operatorname{amp}[c]+$ gthox $[c]+\operatorname{so} 3[c]<=>2$ gthrd $[c]+\operatorname{aps}[c]$ & 0.3186 & -20.0000 \\
\hline 26 & R05794\# & chol $[c]+\operatorname{cdpdag}[c]<=>p c[c]+c m p[c]$ & 0.2051 & -0.0002 \\
\hline 27 & $\mathrm{R} 07171^{\text {\$ }}$ & $\mathrm{O} 2[\mathrm{c}]+\mathrm{h}[\mathrm{c}]+\operatorname{nadh}[\mathrm{c}]<=>\mathrm{h} 2 \mathrm{O} 2[\mathrm{c}]+\operatorname{nad}[\mathrm{c}]$ & 0.2079 & -0.1820 \\
\hline 28 & $\mathrm{R} 07172^{\$}$ & $\mathrm{o} 2[\mathrm{c}]+\mathrm{h}[\mathrm{c}]+\operatorname{nadph}[\mathrm{c}]<=>\mathrm{h} 2 \mathrm{o} 2[\mathrm{c}]+\operatorname{nadp}[\mathrm{c}]$ & 0.2125 & -0.2089 \\
\hline
\end{tabular}

${ }^{\$}$ Direct formation of oxygen; ${ }^{*}$ Indirect formation of oxygen through $\mathrm{H}_{2} \mathrm{O}_{2} ;{ }^{*}$ Reactions selected for further analysis

orotate. The URA1 gene from S. cerevisiae, which converts dihydroortate to orotate with fumarate added to the medium as electron acceptor, was reported to result in enhanced anaerobic growth in S. stipitis [15]. This serves as a validation of the model developed for $S$. stipitis.

Model simulations were also carried out with xylose as the carbon source. The gene candidate identified for anaerobic growth on glucose resulted in a very low biomass flux. This flux was observed when xylose reductase activity was solely dependent on NADH and there was no flux when xylose reductase enzyme used NAPDH or a ratio of NADH and NADPH. S. stipitis strain with URA1 gene was not able to grow on xylose under anaerobic conditions [15]. In addition to biosynthetic requirements, further analysis has to be performed on energy, redox balance and regulatory requirements to understand the limitations for anaerobic growth on xylose.

\section{Xylose utilization by scheffersomyces stipitis}

Xylose is generally utilized by a two-step oxidoreductase reaction catalyzed by xylose reductase and xylitol dehydrogenase. The difference in cofactor specificity between these two reactions often hinders the utilization of xylose and results in the production of xylitol $[41,42]$. The $S$. stipitis xylose reductase accepts both NADPH and NADH as cofactors with higher preference for NADPH [43] and the xylitol dehydrogenase utilizes NAD as a cofactor. However, xylitol accumulation was found to be negligible in S. stipitis [44]. This aspect was analyzed using the model developed for $S$. stipitis. Model simulations were carried out for various ratios of NADPH and NADH dependent xylose reductase and for various uptake rates of xylose and oxygen. No xylitol accumulation was observed in these simulations. The capability of S. stipitis to efficiently interconvert NADPH and NADH might be a reason for lower xylitol accumulation. However when 
the xylose reductase activity was more dependent on $\mathrm{NADPH}$ and under lower oxygen uptake rates, it was observed that the xylose uptake rates were limited by oxygen uptake rate (Figure 5). The dependence of xylose uptake rate on oxygen transfer rates has been observed in S. stipitis [44] and the substrate consumption rates were improved by having higher initial cell concentration [45].

Reaction insertion analysis used for the identification of metabolic requirements for anaerobic growth was used to identify reactions that enable enhanced uptake of xylose under this condition. Several reactions were able to enhance xylose uptake rate and biomass flux [Data not shown]. A majority of these reactions were able to enhance the uptake rate of xylose by the effective production of the cofactors NADPH and NAD. This was evident when the reversible transdehydrogenase reaction which inter converts NADPH and NAD to NADH and NADP was introduced. This indicates that the metabolic network of $S$. stipitis lacks a sufficient NADPH forming transdehydrogenase reaction.

The production of ethanol from xylose by $S$. stipitis was analyzed using the model. The existence of an optimal oxygen uptake rate for maximum ethanol yield was observed in the model simulations as reported in literature [14]. A plot of ethanol production rates at various oxygen uptake rates for various ratios of NADPH and $\mathrm{NADH}$ dependent xylose reductase activity is shown in Figure 6. It is evident that as the dependency of xylose reductase on NADPH increases, the dependence of optimal ethanol production on oxygen uptake rate also increases.

\section{Flux variability analysis of the genome scale metabolic} model

Flux variability analysis (FVA) was carried out for growth on glucose and xylose using the COBRA toolbox. Reactions known to result in loops within the major metabolic pathways were manually removed from the model before performing the flux variability analysis. The normal FVA calculates the minimum and maximum fluxes across various reactions in major metabolic pathways when maximizing the objective function (Biomass Flux). A variant of FVA called the sub-optimal FVA has been found to be more informative [46], wherein instead of fixing the objective value to an optimal value from the initial FBA, objective lower limit was

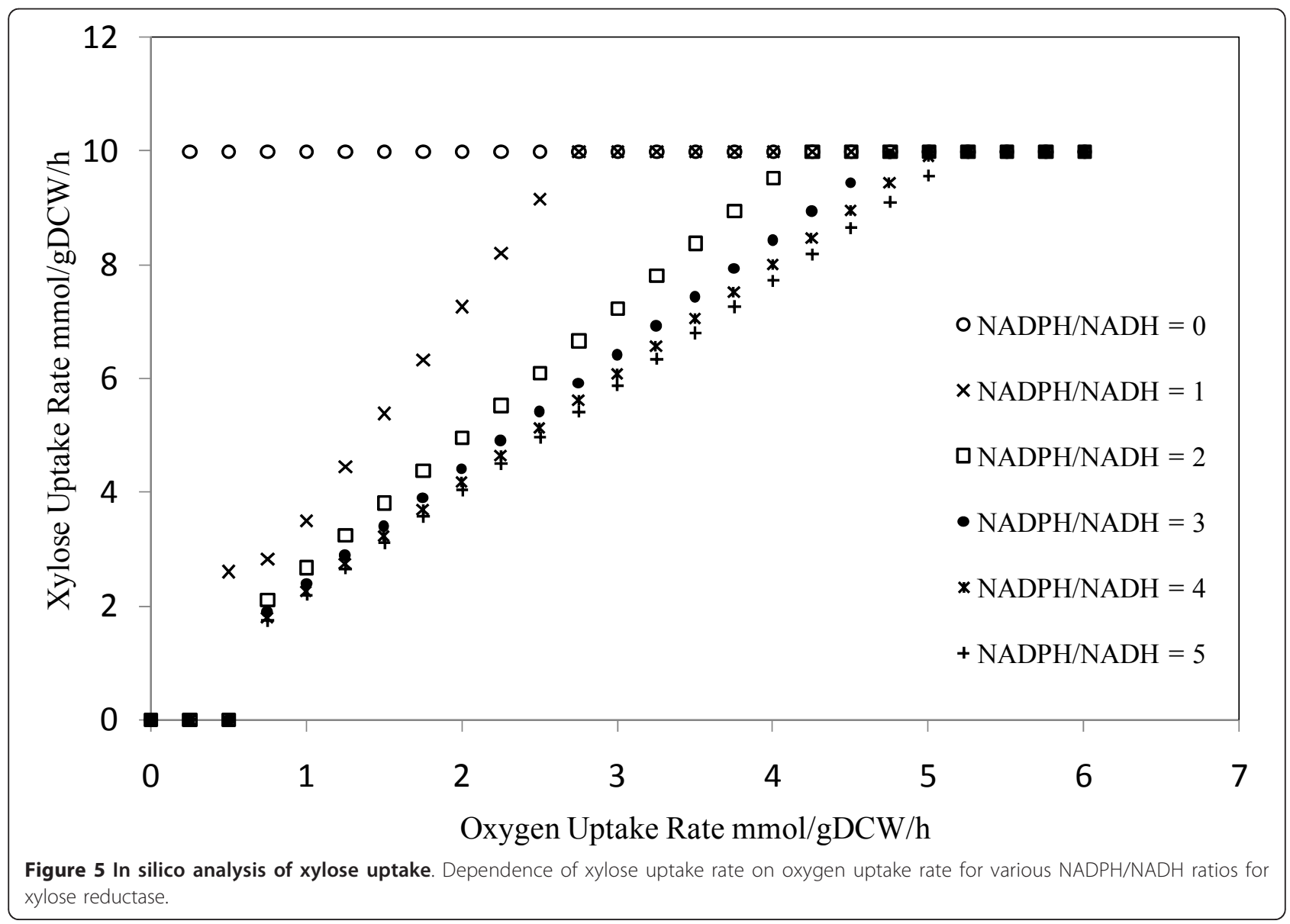




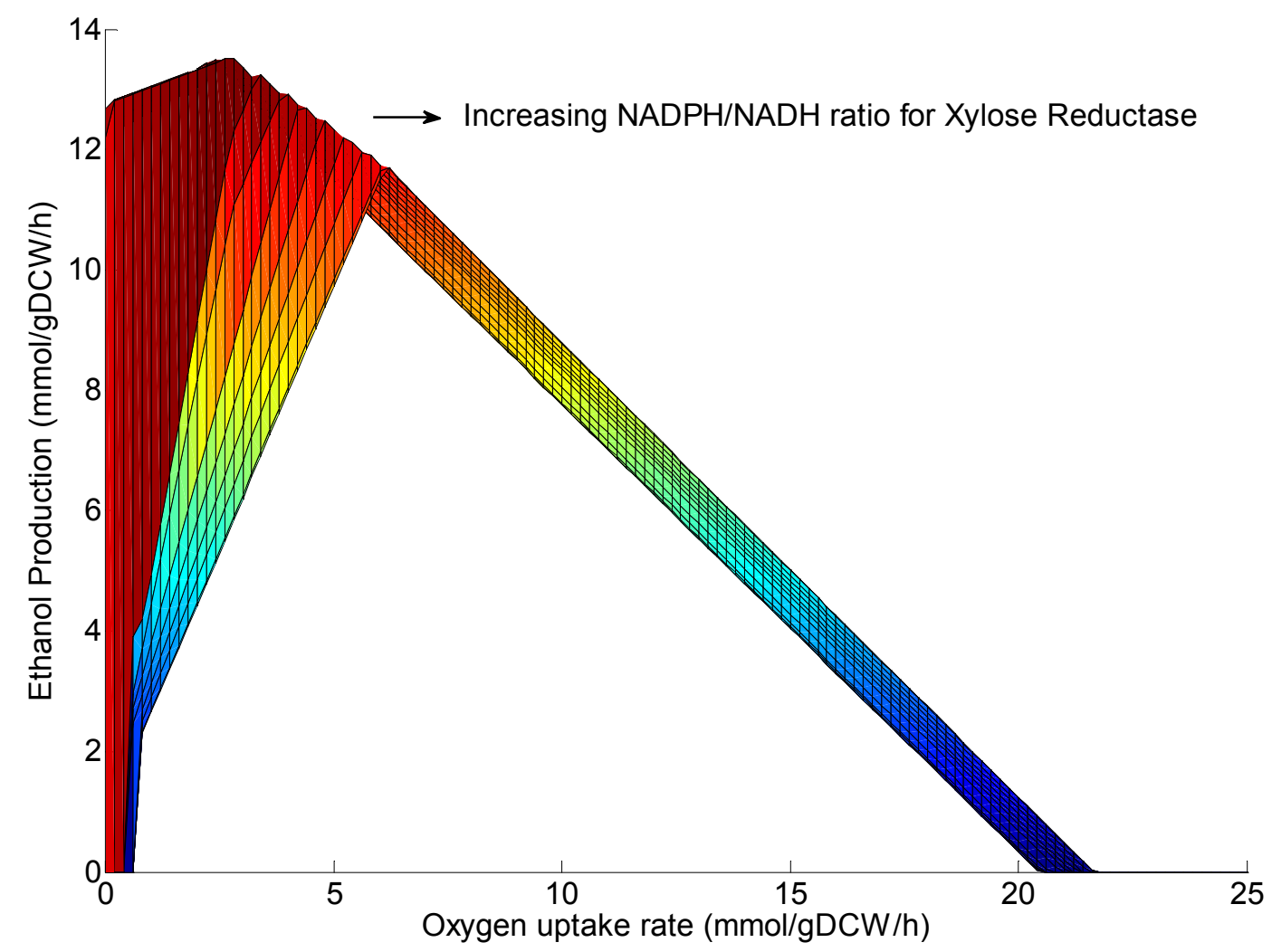

Figure 6 In silico analysis of ethanol production. Ethanol production as function of oxygen uptake rate for various NADPH/NADH ratios for xylose reductase. The NADPH/NADH ratio was varied from zero to a very high value (1000000).

chosen at $95 \%$ of the initial objective value. The normalized flux ranges (normalized with respect to substrate uptake rate) for the major reactions obtained using the suboptimal FVA is shown in supplementary Figures S1S4 (Additional File 5). Experimental values for the metabolic flux distribution in S. stipitis are scarce. The only report on the metabolic flux profiling of S. stipitis compared the central carbon metabolism of this yeast with that of S. cerevisiae [47]. This data cannot be directly compared with the model simulations as the substrate uptake rates and oxygen transfer rates were not reported.

Analysis of the suboptimal flux variability values for major metabolic pathways in S. stipitis metabolic network grown in glucose minimal media revealed a few key reactions which could carry zero flux. One such reaction is phosphoglucose isomerase reaction catalyzed by the pgil gene (PICST_84923). Phosphoglucose isomerase pgi1-deletion mutants of $S$. cerevisiae cannot grow on glucose as the sole carbon source. The inability of $S$. cerevisiae to efficiently recycle the NADPH generated by the oxidative pentose phosphate pathway has been cited as the major reason for this growth defect $[48,49]$. However, in S. stipitis in silico growth rates were not significantly reduced. In silico metabolic flux analysis was performed for the pgi1-mutant $S$. stipitis to obtain insights on various pathways employed by $S$. stipitis to recycle NADPH generated from oxidative pentose phosphate pathway. Several pathways that could recycle cytosolic NADPH were identified in the S. stipitis network. The most promising pathways are listed below

1. NAD-dependent glutamate dehydrogenase and NADP-dependent glutamate dehydrogenase which causes a substrate shuffling between 2-oxoglutarate and glutamate which restores NADP from NADPH through the coupled conversion of NAD to NADH.

2. NADPH dehydrogenase which couples the oxidation of cytoplasmic NADPH to mitochondrial respiratory chain.

3. NAD-dependent alcohol dehydrogenase and NADP-dependent alcohol dehydrogenase which causes a substrate shuffling between ethanol and acetaldehyde which restores NADP from NADPH through the coupled conversion of NAD to NADH.

Comparison of the literature on the phosphoglucose isomerase mutant (pgi1-mutant) S. cerevisiae, Escherichia coli and Kluyveromyces lactis has indicated that the 
above mentioned pathways are either present in these organisms or when introduced has enhanced the growth of these organisms. K. lactis is reported to possess the mitochondrial NADPH dehydrogenase and a transdehydrogenase cycle involving the alcohol dehydrogenase [50,51]. In E. coli and S. cerevisiae the introduction of a soluble transdehydrogenase gene was found to enhance the growth of pgi1-mutants on glucose [47,52]. Further, in S. cerevisiae, over expression of the NAD-dependent glutamate dehydrogenase restored growth in these mutants [49]. From the Biolog phenotype data presented earlier in this paper it can be observed that S. stipitis can grow on glutamate as the sole carbon source. The first step in glutamate utilization is NAD-dependent glutamate dehydrogenase and thus this pathway might be responsible for the growth of pgi1-mutant S. stipitis. However, all these pathways and the pgil-mutant strains have to be evaluated experimentally to confirm their roles. Nevertheless, the analysis highlights the usefulness of the metabolic model developed in the designing microbial strains with desired properties.

Even though S. stipitis metabolic network possesses numerous ways for NADPH consumption, the generation of NADPH and NAD to efficiently utilize xylose under lower oxygen uptake rates was limited. One particular pathway was observed to be induced under oxygen limited conditions when the cells are grown on xylose and this pathway was considered to be effective in tackling the cofactor imbalance caused by the first two steps in xylose utilization [25,53]. This pathway involved the four enzymes; NAD-dependent glutamate dehydrogenase (GDH2) which converts 2-oxoglutarate to L-glutamate consuming NADH, glutamate decarboxylase (GAD2) which decarboxylates L-glutamate to 4-aminobutyrate, 4-aminobutyrate aminotransferase (UGA1.1 or UGA1.2) which transaminates 4-aminobutyrate to Succinate semialdehyde and Succinate semialdehyde dehydrogenase (UGA2 or UGA2.2) which oxidizes Succinate semialdehyde to Succinate using NADP (Figure 7). The net result is the conversion of NADH to NADPH. However, the suboptimal flux variability analysis shows that flux through this pathway is limited (maximum of about $35 \%$ of substrate uptake rate) and the maximum flux achievable is very low under oxygen limited conditions (about 1-2\% of substrate uptake rate) when biomass is maximized. This flux may not be sufficient to generate enough NADPH to increase the substrate uptake rates.

\section{Mechanism of mitochondrial respiration and oxidative phosphorylation}

The role of the model in enhancing the understanding of cellular phenotypes and identifying requirements for metabolism were explained in the previous sections. In addition, the model can also be used to probe mechanisms in metabolism of a microorganism. In this section, the mechanisms involved in mitochondrial respiration and oxidative phosphorylation are analyzed using the model developed.

S. stipitis is known to possess a branched respiratory chain which composes of the basic respiratory chain complexes I-IV, an alternative oxidase and alternative NADH dehydrogenases [54]. The effect of inhibition of various complexes in the respiratory chain on the growth of S. stipitis has been investigated [55]. Experiments have been carried out to study the role of cytochrome- $\mathrm{C}$ oxidase and alternative oxidase on respiration and growth of S. stipitis [56-58]. However, a consistent mechanism that explains the mechanism of mitochondrial respiration and oxidative phosphorylation was not immediately evident from these experimental data. To further investigate the mechanism of oxidative phosphorylation in S. stipitis, simulations were carried out using the model developed. Simulations were able to predict increase in the ethanol yield observed in a cytochrome-C mutant [57]. However, a simple knockout of individual components of the respiratory chain was not sufficient to explain all the experimental observations reported. The comparison of qualitative model simulations with the experimental data obtained for growth on glucose and xylose is shown in Table 3 . The structure of model suggests that all components in the respiratory system are always available and organized into a pathway as needed (when optimized for a particular objective). However this may be not true in the real situation.

\section{Discussion}

One of the well established ways by which microorganisms attain different phenotypic characteristics is by gene regulation. However, in the case of mitochondrial respiration, channeling the electron flow by the formation of super-complexes has been reported as a common mechanism [59-62]. Analysis of the inhibition data on glucose and xylose suggest that either the alternative oxidase or the alternate NADH dehydrogenase may be repressed when grown on glucose. However, studies on cytochrome-C mutants suggest that alternative oxidase may be expressed constitutively $[56,57]$. Various hypothetical complexes were analyzed through model simulations and were then combined with regulation of gene expression (alternative NADH dehydrogenase) to result in a mechanism which explains all the experimental observations qualitatively. Based on the analysis, the complex formation between alternate oxidase and either Complex III or Complex IV is critical to explain the experimental observations. The proposed mechanism was also able to predict the observed increase in the growth yield in the presence of SHAM (an alternative oxidase inhibitor) during the growth of S. stipitis on xylose [56]. This again 


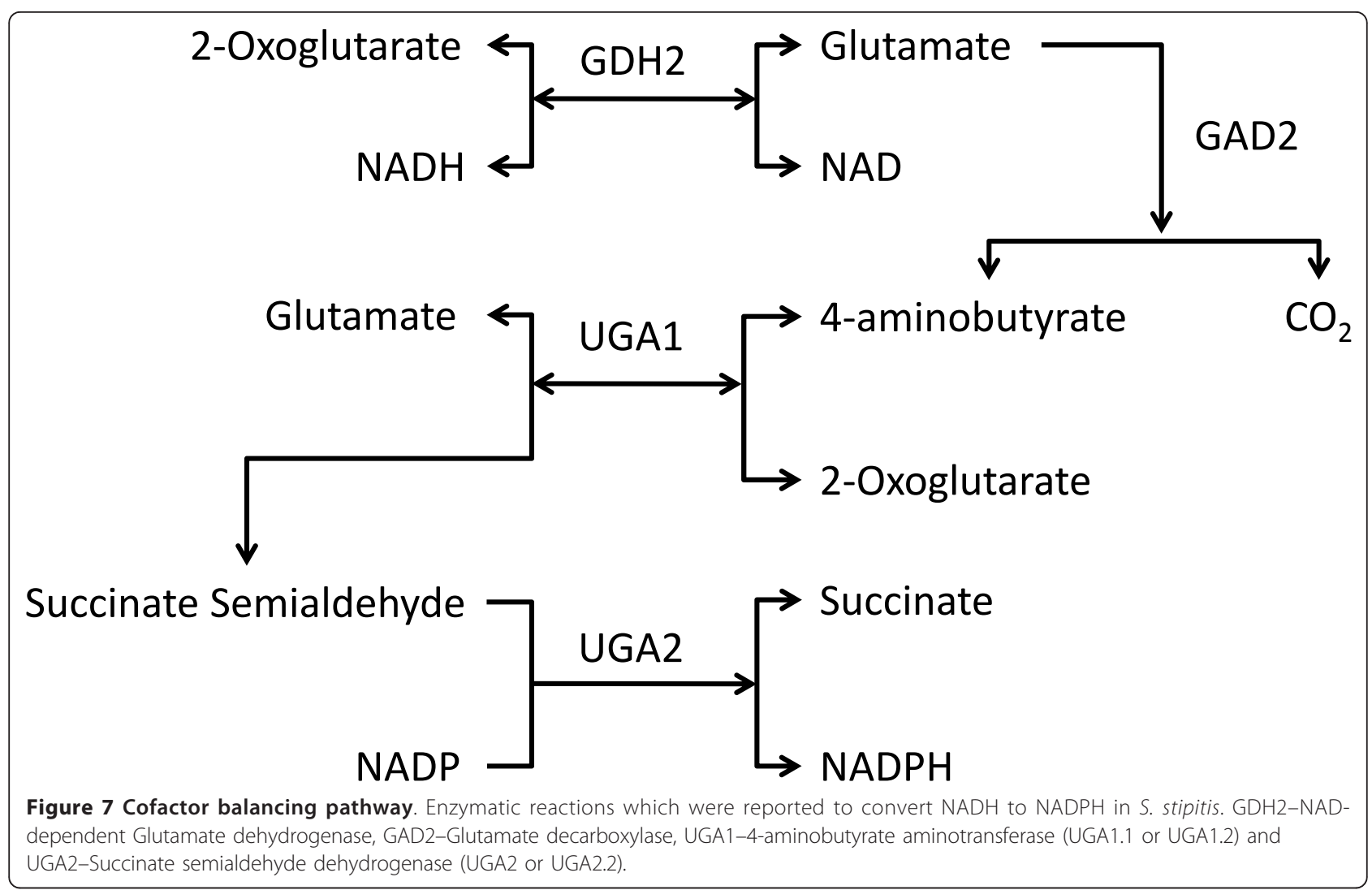

highlights the utility of model in enhancing our understanding of metabolism of an organism.

An iterative procedure has been designed and used to develop the genome scale metabolic model of S. stipitis.
The procedure begins with the reconstruction of genome scale metabolic network which is then converted to a fully functional in silico model by incorporating the experimentally determined macromolecular composition,

Table 3 Effect of inhibition of various mitochondrial respiratory complexes on the growth of Scheffersomyces stipitis in glucose and xylose. (-) Complete Inhibition; (-) Partial Inhibition; (0) Negligible; (++) Enhanced; NA - Information not available

\begin{tabular}{|c|c|c|c|c|c|}
\hline \multirow[t]{2}{*}{ Complex/Inhibitor } & \multicolumn{2}{|c|}{ Effect on Growth } & \multicolumn{2}{|c|}{$\begin{array}{l}\text { Effect on Growth Complex formation AOX and Complex } \\
\text { III or IV (Predicted from model analysis) }\end{array}$} & \multirow[t]{2}{*}{ References } \\
\hline & $\begin{array}{l}\text { Glucose } \\
\text { (in Vivo/ } \\
\text { In Silico) }\end{array}$ & $\begin{array}{l}\text { Xylose } \\
\text { (in Vivo/ } \\
\text { In Silico) }\end{array}$ & $\begin{array}{l}\text { Glucose } \\
\text { (in Vivo/ } \\
\text { In Silico) }\end{array}$ & $\begin{array}{l}\text { Xylose } \\
\text { (in Vivo/ } \\
\text { In Silico) }\end{array}$ & \\
\hline $\begin{array}{l}\text { Complex I } \\
\text { (Rotenone) }\end{array}$ & $(-/ 0)$ & $(-/ 0)$ & $(-/-)$ & $(-/-)$ & Shi et al., 2002 \\
\hline $\begin{array}{l}\text { Complex III } \\
\text { (Antimycin A) }\end{array}$ & $(\mathrm{NA} /-)$ & $(-/-)$ & $(\mathrm{NA} /-)$ & $(-/-)$ & $\begin{array}{l}\text { Lighthelm et } \\
\text { al., } 1988\end{array}$ \\
\hline$\overline{A O X}($ SHAM) & $(0 / 0)$ & $(++/ 0)$ & $(0 / 0)$ & $(++/++)$ & Jeppsson et al., 1995 \\
\hline $\begin{array}{l}\text { Complex IV } \\
\text { (Cyanide) }\end{array}$ & $(-/-)$ & $(-/-)$ & $(-/-)$ & $(-/-)$ & Jeppsson et al., 1995 \\
\hline $\begin{array}{l}\text { Complex IV and } \\
\text { AOX (Sodium Azide) }\end{array}$ & $(\mathrm{NA} /-)$ & $-/-)$ & $(\mathrm{NA} /-)$ & $-(-)$ & Lighthelm et al., 1988 \\
\hline Complex IV(Cyanide) and AOX (SHAM) & $(-/-)$ & $(-/-)$ & $(-/-)$ & $(-/-)$ & Jeppsson et al., 1995 \\
\hline \multicolumn{6}{|l|}{ Mutant/Inhibition combination } \\
\hline Complex I (Rotenone) + del AOX & $(-/ 0)$ & $(-/ 0)$ & $(-/-)$ & $(-/-)$ & Shi et al., 2002 \\
\hline Complex I (Rotenone) + del Complex IV & $(-/-)$ & $(-/-)$ & $(-/-)$ & $(-/-)$ & Shi et al., 2002 \\
\hline
\end{tabular}


maintenance coefficients and minimal medium requirements. Even though assumption of macromolecular composition based on other related microorganisms or compiling fragmented data from different sources is a common practice [46,63-65], it may lead to improper predictions of essential genes and metabolic flux distribution. Determination of macromolecular composition is critical as it defines the minimal number of metabolites that has to be produced for growth and the relative contribution of these metabolites to growth. Further, it helps in refinement of the genome annotation as some pathways producing these metabolites might not be annotated properly. In the case of S. stipitis, higher content of chitin is observed as compared to other yeasts like S. cerevisiae (chitin is not a part of the biomass equation used for S. cerevisiae genome scale model [33]). Similarly, phosphatidyl-inositol was found in S. stipitis biomass but a pathway enzyme which converts myo-inositol to inositol was not annotated in S. stipitis genome. A homolog was identified for this enzyme (PICST_63214) and was incorporated into the model. The in silico model was validated for consistency against newly generated highthroughput substrate phenotyping data. The model was subjected to iterative refinements based on identified inconsistencies, leading to additional reactions incorporated into the network and other modifications to the model content. The net result is a biochemically and genetically detailed in silico model that consists of 1371 reactions that are catalyzed by 814 genes. To our knowledge this is the first genome scale metabolic model developed for S. stipitis and it qualitatively predicts the phenotypic behaviors for substrate utilization with $74 \%$ agreement (252 out of 339 cases).

The model developed has also generated several experimentally verifiable hypotheses that could provide insight into the metabolism of S. stipitis. Generation of new annotation for metabolic genes based on networkbased gap analysis and high-throughput phenotyping is one such example. Another example is the insight obtained on the mechanism involved in mitochondrial respiratory chain of $S$. stipitis. The results of the inhibition experiments carried out for the various complexes in the mitochondrial respiration chain where explained based on a hypothetical complex formation using in silico metabolic flux analysis. The hypothetical complex formation has to be verified by designing appropriate experiments. Further, the formation of mitochondrial super complexes has already been reported in several yeasts like S. cerevisiae and Yarrowia lipolytica [61,62].

The predictive capability of the genome scale metabolic network was demonstrated by identifying the biosynthetic requirements for anaerobic growth of $S$. stipitis. The gene insertion analysis performed on the metabolic model was able to identify the particular conversion essential for anaerobic growth on glucose and this was validated by comparing with literature. However, the identified reaction did not enable in silico growth on xylose and this was also observed in experiments [15]. As mentioned in the results sections anaerobic growth is a complex phenotype with biosynthesis complemented by energy, redox balance and regulatory requirements. However, the ability to grow on glucose under anaerobic condition suggests that anaerobic growth on xylose can also be achieved if the other requirements are analyzed systematically. In silico analysis revealed that unconstrained supply of ATP could support anaerobic growth on xylose. Many pathways are known to generate ATP. For example, the bacterial acetate production pathway is commonly employed to improve ATP production [66]. Since acetate has been reported to inhibit xylose fermentation in S. stipitis [67], other pathways for ATP generation needs to be investigated. Further redox balance requirements and regulatory requirements should also be considered when developing strategies to promote anaerobic growth.

Xylose uptake analysis carried out using the model indicated that S. stipitis metabolic network may not possess sufficient NADPH and/or NAD generation capability under lower oxygen uptake rates. Even though $S$. stipitis is considered to be an efficient xylose utilizing yeast, the metabolic model developed emphasizes the need for further characterization of this yeast to understand and improve its fermentation performance. High throughput techniques routinely used in the characterization of industrial yeasts like $S$. cerevisiae should also be developed for S. stipitis. Furthermore, analysis of pgi1-mutant shows that $S$. stipitis metabolic network possess many pathways to consume NADPH and recycle NADP. When grown on glucose the xylose utilization pathway itself can be considered as one such pathway. Thus by performing a detailed analysis on the various NADP recycling pathways and carefully designing suitable mutants the S. stipitis metabolic network can be optimized for simultaneous consumption of glucose and xylose. This trait has been a subject of active investigation and is of industrial significance [68].

\section{Conclusion}

In this study, we have reconstructed a genome scale metabolic model for S. stipitis by combining information from genome sequence annotation, pathway databases, literature and experimental data. The model was refined using high-throughput phenotyping data. The model predictions were in good agreement with experimental observations, thus allowing us to systematically investigate the physiological characteristics and metabolic capability of this yeast. In silico model analysis shows that S. stipitis possesses several pathways to recycle 
nucleotide cofactors and thus efficient xylose utilization. However, the flux through of these pathways needs experimental investigation. Analysis of mitochondrial respiration and identification of mitochondrial supercomplexes demonstrate the novel applications of the model developed. Incorporation of thermodynamic constraints, enzyme kinetics information and high-throughput omics data can further improve the predictability of these models

\section{Materials and methods \\ Metabolic network reconstruction}

Figure 1 outlines the overall procedure for reconstruction and validation of the genome scale metabolic model for S. stipitis. The entire procedure is based on the recently published protocol for generation of genome scale metabolic models [32]. The reconstruction process was initiated based on annotated genome of Scheffersomyces stipitis [25] and ORF (open reading frame) information available on the National Centre for Biological Information http://www.ncbi.nlm.nih.gov/. The biochemical reactions corresponding to the ORFs were mainly compiled from KEGG Database $[40,69,70]$ and MetaCyc Database [71], resulting in a draft reconstruction comprising of enzymes and metabolic reactions.

The next step is the refinement of the draft. For each reaction, gene-protein-reaction association, localization, cofactor specificity, and directionality were identified and assigned. The gene-protein-reaction associations include definitions for isoenzymes and enzyme complexes. The metabolic reactions in the model were organized into three compartments (Cytoplasm, Mitochondria and Extracellular) based on the localization of associated enzymes, which was obtained using the protein localization predictors [72,73] (Lu et al., 2004; Claros and Vincens, 1996). The cofactor and substrate specificity and reaction directionality information were compiled from available literature information, completed genome scale reconstructions [33,63,74-76] and BRENDA database $[77,78]$. The reactions were then organized into pathways/subsystems. For each metabolite, the charge, formula and identification information were compiled from KEGG database and BIGG database. In the next step, some spontaneous and non-gene associated reactions whose existence was supported by physiological or experimental data from the literature and databases were included. In addition to these reactions, exchange reactions and intracellular and extracellular transport reactions were added. The genes associated with the transport reactions were identified using the transport protein predictor [79]. The final step is the incorporation of biomass equation and, growth and non-growth associated maintenance coefficient.
The final reconstruction was then loaded into Matlab and the in silico model obtained was evaluated for its capability to produce biomass precursors and known byproducts from minimal media and gaps in the metabolic network were identified. The gaps were then filled based on pathway databases and published reconstructions. The dead-end reactions in the network were identified and appropriate exchange reactions were added when applicable. The model was then refined and validated iteratively using Biolog phenotyping data. The final model was used for the simulation studies.

\section{Biomass macromolecular composition estimation Media and cultivation conditions}

Scheffersomyces stipitis CBS 6054 (CBS6054 = ATCC $58785=$ NRRL Y-11545 = IFO 10063) was purchased from American Type Culture Collection. It was routinely cultured in yeast extract, peptone, dextrose (YPD) medium and samples were collected at the exponential growth phase for the estimation of biomass macromolecular composition. Experimental data for biomass composition estimation were collected in duplicates and average values obtained are reported. For growth rate and substrate uptake rate measurements, experiments were carried out in minimal media containing $0.17 \%$ yeast nitrogen base without amino acids, $0.5 \%$ ammonium sulphate and 2\% glucose. Experiments were carried out in 1 liter Erlenmeyer flasks at $30^{\circ} \mathrm{C}$ and $200 \mathrm{rpm}$. The $\mathrm{OD}_{600}$ was measured periodically for several hours to calculate the growth rates and the supernatant was collected and analyzed using HPLC for calculating the substrate uptake rates. The macromolecular composition of S. stipitis biomass was estimated by measuring carbohydrate, protein, lipid and nucleic acid content and the components making up these macromolecules.

\section{Biomass carbohydrate content}

The cell wall polysaccharides (Glucan, Mannan and Chitin) and intracellular carbohydrates (Glycogen and Trehalose) together contribute to the total carbohydrate content. Cell wall isolation and quantification of polysaccharides in the cell wall was carried out as described by Francois, 2007 [80]. Cells were harvested and then lyzed using glass beads in a homogenizer. The cell wall was separated by high speed centrifugation and dried. The supernatant was used for nucleic acid analysis. The dried cell wall was hydrolyzed with $72 \%$ sulphuric acid and the sugars liberated were analyzed using HPLC. Glucan and Mannan content was estimated from these liberated sugars. Laminarin and Mannan were used for calibration and galactose was used as the internal standard. For the analysis of chitin content, the cell wall was heated with $6 \% \mathrm{KOH}$ to liberate chitin. The chitin was treated with chitinase to liberate glucosamine which was detected using Reissig's reagent. Glycogen content was 
determined as explained by Smolders et al., 1994 [81]. Approximately $20 \mathrm{mg}$ of lyophilised cells was resuspended in $10 \mathrm{ml}$ of $0.6 \mathrm{M} \mathrm{HCl}$ and boiled on a heating block at $100^{\circ} \mathrm{C}$ for $1 \mathrm{~h}$. Glucose liberated from glycogen hydrolysis was quantified using HPLC. For the measurement of trehalose content, cells were washed twice with cold water and resuspended in $3 \mathrm{ml}$ of water for $15 \mathrm{~min}$ at $100^{\circ} \mathrm{C}$. Sample was incubated overnight with trehalase in $60 \mathrm{ul}$ of acetate buffer. Glucose liberated from trehalose hydrolysis was quantified using HPLC.

\section{HPLC analysis of sugars}

The sugars glucose and mannose was measured by HPLC using the Biorad Aminex HPX-87H column. $5 \mathrm{mM}$ Sulphuric acid was used as mobile phase and sugars were detected using RID detector operating at $50^{\circ} \mathrm{C}$.

\section{Biomass protein and amino acid content}

Total protein content of S. stipitis biomass is determined using nitric acid method [82]. The harvested cells were washed in TE buffer and centrifuged. The cells were then solubilized in 70\% nitric acid and incubated at $22^{\circ} \mathrm{C}$ for $24 \mathrm{~h}$. The absorbance was measured at 358 $\mathrm{nm}$ to obtain the protein content. Calibration curves for protein estimation were obtained using BSA. The amino acid content of S. stipitis biomass was measured using standard protocols as explained in AOAC Official Method 994.12 and AOAC Official Method 985.28 [83].

\section{Biomass nucleic acid content}

The DNA and RNA content was determined using Orcinol reagent $\left(0.1 \%\right.$ Orcinol, $0.1 \% \mathrm{FeCl}_{3} \cdot 6 \mathrm{H}_{2} \mathrm{O}$ in concentrated $\mathrm{HCl}$ ) [84]. Freeze-dried cell lysate was resuspended and diluted in autoclaved MilliQ water for DNA and RNA analysis. Equal volumes of diluted sample and freshly prepared Orcinol reagent were mixed and incubated at $100^{\circ} \mathrm{C}$ for either 2 min (for DNA estimation) or $15 \mathrm{~min}$ (Total nucleic acid estimation). The mixtures were immediately cooled on ice. The mixture incubated for $2 \mathrm{~min}$ was further incubated at $37^{\circ} \mathrm{C}$ for $2 \mathrm{~h}$ after cooling on ice. The absorbance was measured at $600 \mathrm{~nm}$ to obtain the DNA and total nucleic acid content. The values obtained from DNA measurements were subtracted from the total nucleic acid values to obtain the RNA content of the cell lysate. Calibration curves were obtained using standard DNA and RNA.

\section{Biomass lipid content}

The total lipid content was determined as explained by Matyash et al., 2008 [85]. Harvested cells were washed twice with $10 \mathrm{ml}$ of $0.1 \%$ ammonium acetate solution and resuspended in $6 \mathrm{ml}$ of ammonium acetate solution. Optical density was measured and $5 \mathrm{ml}$ of cell suspension was added to $7.5 \mathrm{ml}$ of methanol and vortexed vigorously. $25 \mathrm{ml}$ of methyl-tert-butyl ether was added and the mixture was shaken at $250 \mathrm{rpm}$ for $1 \mathrm{~h}$. Cell debris was removed by filtration and $6.25 \mathrm{ml}$ of water was added to the mixture. The organic phase was extracted twice with the solvent mixture and dried in a preweighed round bottom flask. Lipid content was then calculated based on the weight of the lipids extracted. The individual lipid classes were measured using TLC. Polar lipids were separated on a silica gel TLC plate with chloroform/methanol/water (65:25:4) as an eluent as described by Skipski et al., 1962 [86]. Neutral lipids were separated on a silica gel TLC plate with hexane/ Diethyl ether/formic acid (45:5:1) as an eluent as described by Low et al., 2009 [87]. The separated lipids were quantified by densitometry using standard lipids. The fatty acid composition of S. stipitis was obtained using standard protocols as explained in AOAC Official Method 996.06 [83].

The composition of the various biomass macromolecules estimated were converted to a biomass synthesis equation to be incorporated into to model developed. The growth and substrates uptake data estimated in the present study, along with reported data from continuous cultivation experiments [88] were used to calculated the growth and non-growth associated maintenance coefficients (Refer to Additional File 1 for details).

\section{In silico computations}

The metabolic network was loaded into Matlab using functions available in the COBRA toolbox $[89,90]$. The metabolic capabilities of S. stipitis network were calculated by using flux balance analysis and linear optimization. For growth simulations, biomass synthesis was selected as the objective to be maximized and the optimization was solved using the COBRA Toolbox. The external metabolites were allowed to freely cross the system boundary by having unconstrained exchange reaction. Units of all flux values are in $\mathrm{mmol} / \mathrm{gDCW} / \mathrm{h}$. For the simulation of aerobic growth on minimal media, the following external metabolites were allowed to freely enter and leave the network: $\mathrm{NH}_{4}, \mathrm{O}_{2}, \mathrm{H}+, \mathrm{SO}_{4}, \mathrm{PO}_{4}, \mathrm{CO}_{2}$ and $\mathrm{H}_{2} \mathrm{O}$ (exchange fluxs $-1000-1000 \mathrm{mmol} / \mathrm{gDCW} / \mathrm{h}$ ). All other external metabolites, except the substrates tested were only allowed to leave the system (exchange fluxes 0$1000 \mathrm{mmol} / \mathrm{gDCW} / \mathrm{h}$ ). Growth on different substrates was simulated by allowing the corresponding external metabolite to enter the system with the definite exchange rate $(10 \mathrm{mmol} / \mathrm{gDCW} / \mathrm{h})$. For the simulation of anaerobic growth, oxygen uptake was reduced to zero and unconstrained uptake of sterols and unsaturated fatty acids was allowed.

\section{Phenotype microarray analysis of scheffersomyces stipitis}

Biolog's Phenotype MicroArray ${ }^{\mathrm{TM}}$ technology [34] was used for the phenotypic analysis of Scheffersomyces stipitis. It permits assays of 190 carbon (PM1- and PM2A- microplates), 95 nitrogen (PM3BMicroplate), 59 phosphorus 
and 35 sulphur-source (PM4A-Microplate) utilizations at once. A defined medium containing $100 \mathrm{mM}$ glucose, 5.0 $\mathrm{mM} \mathrm{NH} 4 \mathrm{Cl}, 2.0 \mathrm{mM} \mathrm{NaH} 2 \mathrm{PO} 4,0.25 \mathrm{mM} \mathrm{Na} 2 \mathrm{SO} 4,100$ $\mathrm{mM} \mathrm{NaCl}, 30 \mathrm{mM}$ triethanolamine $\mathrm{HCl}(\mathrm{pH} 7.1), 0.05$ $\mathrm{mM} \mathrm{MgCl} 2,1.0 \mathrm{mM} \mathrm{KCl}, 1.0 \mathrm{mM} \mathrm{FeCl} 3$, and $0.01 \%$ tetrazolium violet was used for the PM tests. The PM plates contained various carbon-, nitrogen-, phosphorus-, or sulphur-sources which are omitted from the defined medium. The microplates were incubated at $30^{\circ} \mathrm{C}$ and the dye reduction data were collected in 15-min intervals for $48 \mathrm{~h}$. In addition to time profile dye reduction data, the absorbance was measured at $590 \mathrm{~nm}$ and $750 \mathrm{~nm}$ after $24 \mathrm{~h}$ and $48 \mathrm{~h}$ incubations. The colorimetric assay was considered positive when the absorbance corresponding to reduced dye was 1.2 times higher than the negative control. Similar threshold was applied for the absorbance at $750 \mathrm{~nm}$. The threshold was set at 1.3 for sulphur source data as the negative control was observed to have a higher background. The confidence with which growth can be predicted based on these measurements was determined based on the number of positive reactions out of 4 absorbance measurements. High confidence growth $(+)$ if all measurements were above threshold and high confidence no-growth (-) if below. The remaining cases were classified as low-confidence data.

\section{Additional material}

Additional file 1: Estimation of growth and non-growth associated maintenance requirements.

Additional file 2: Details of the reactions and metabolites in the genome scale metabolic model of Scheffersomyces stipitis. Additional file 3: List of essential reactions in the genome scale model.

Additional file 4: Comparison of model predictions and Biolog substrate utilization data. The details of substrates tested, abbreviations used for these substrates in the model, additional experimental evidence and model refinements are described in this file.

Additional file 5: Sub-Optimal Flux variability analysis of Scheffersomyces stipitis metabolic model (Figures S1-S4).

\begin{abstract}
Acknowledgements
We thank Dr. Dong-Yup Lee (Department of Chemical and Biomolecular Engineering, National University of Singapore) for valuable discussions on the reconstruction procedure. We also thank Dr Zhao Hua (Industrial Biotechnology Group, ICES, A*STAR) for suggestions on biomass composition estimation and Dr. Cletus P. Kurtzman (Microbial Genomics and Bioprocessing Research Unit, National Center for Agricultural Utilization Research, ARS, USDA) for sending Pichia stipitis strain to Biolog for phenotype microarray studies. We thank Dr. Michael Ziman (Biolog Inc.) for technical support during the design of phenotype microarray experiments. Financial support from ICES is gratefully acknowledged (project numbers
\end{abstract} ICES08-132002 and ICES/10-234A01).

\section{Author details}

${ }^{1}$ Institute of Chemical and Engineering Sciences, Agency for Science, Technology and Research, 1, Pesek Road, Jurong Island, Singapore 627833, Singapore. ${ }^{2}$ Department of Chemical and Biomolecular Engineering, National
University of Singapore, 10, Kent Ridge Crescent, Singapore 119260 Singapore.

\section{Authors' contributions}

$\mathrm{BB}$ and $\mathrm{SJ}$ designed the model development framework. BB executed the model development work. LT and BB designed the experiments and collected the data. BB and SJ involved in the analysis of results. RS supervised the study and assisted in implementation. BB drafted the manuscript. All the authors read and approved the final manuscript.

\section{Competing interests}

The authors declare that they have no competing interests.

Received: 21 December 2011 Accepted: 23 February 2012

Published: 23 February 2012

\section{References}

1. Kurtzman CP, Suzuki M: Phylogenetic analysis of the ascomycete yeasts that form coezyme Q-9 and the proposal of the new genera Babjeviella, Meyerozyma, Millerozyma, Priceomyces and Scheffersomyces. Mycoscience 2010, 51:2-14.

2. Suh SO, Marshall CJ, McHugh JV, Blackwell M: Wood ingestion by passalid beetles in the presence of xylose-fermenting gut yeasts. Mol Ecol 2003, 12:3137-3145.

3. Nardi JB, Bee CM, Miller LA, Nyugen NH, Suh SO: Blackwell M Communities of microbes that inhabit the changing hindgut landscape of a subsocial beetle. Arthropod Struct Dev 2006, 35:57-68.

4. van Dijken JP, van den Bosch E, Hermans JJ, de Miranda LR, Scheffers WA: Alcoholic fermentation by 'non-fermentative' yeasts. Yeast 1986, 2:123-127.

5. du Preez JC, van Dreissel B, Prior BA: Ethanol tolerance of Pichia stipitis and Candida shehatae strains in fed-batch cultures at controlled low dissolved oxygen levels. Appl Microbiol Biotechnol 1989, 30:53-58.

6. Ferrari MD, Neirotti E, Albornoz C, Saucedo E: Ethanol-production from eucalyptus wood hemicellulose hydrolysate by Pichia stipitis. Biotechnol Bioeng 1992, 40:753-759.

7. Nigam JN: Development of xylose-fermenting yeast Pichia stipitis for ethanol production through adaptation on hardwood hemicellulose acid prehydrolysate. J Appl Microbiol 2001, 90:208-215.

8. Nigam JN: Ethanol production from hardwood spent sulphite liquor using an adapted strain of Pichia stipitis. J Ind Microbiol Biotechnol 2001, 26:145-150.

9. Yang WW, Marks JA, Davies BP, Jeffries TW: High-Efficiency transformation of Pichia stipitis based on its URA3 gene and a homologous autonomous replication sequence, ARS2. Appl Environ Microbiol 1994, 60(12):4245-4254.

10. Lu P, Davis BP, Hendrick J, Jeffries TW: Cloning and disruption of the $\beta$ isopropylmalate dehydrogenase gene (LEU2) of Pichia stipitis and with URA3 and recovery of the double auxotroph. Appl Microbiol Biotechnol 1998, 49:141-146.

11. Laplaza JM, Torres BR, Jin YS, Jeffries TW: Sh ble and Cre adapted for functional genomics and metabolic engineering of Pichia stipitis. Enzyme Microb Technol 2006, 38:741-747.

12. Jin YS, Cruz J, Jeffries TW: Xylitol production by a Pichia stipitis Dxylulokinase mutant. Appl Microbiol Biotechnol 2005, 68:42-45.

13. Ilmen M, Koivuranta K, Ruohonen L, Suominen P, Penttila M: Efficient production of I-lactic acid from xylose by Pichia stipitis. Appl Environ Microbiol 2007, 73:117-123.

14. Grootjen DRJ, van der Lans GJM, Luyben KChAM: Effects of the aeration rate on the fermentation of glucose and xylose by Pichia stipitis CBS 5773. Enzyme Microb Technol 1990, 12:20-23.

15. Shi $X Q$, Jeffries TW: Anaerobic growth and improved fermentation of Pichia stipitis bearing a URA1 gene from Saccharomyces cerevisiae. Appl Microbiol Biotechnol 1998, 50:339-345.

16. Johansson B, Hahn-Hagerdal B: The non-oxidative pentose phosphate pathway controls the fermentation rate of xylulose but not of xylose in Saccharomyces cerevisiae TMB3001. FEMS Yeast Res 2002, 2:277-282.

17. Karhumaa K, Hahn-Hagerdahl B, Gorwa-Grauslund MF: Investigation of the limiting metabolic steps in the utilization of xylose by recombinant Saccharomyces cerevisiae using metabolic engineering. Yeast 2005, 22:359-368. 
18. Kotter P, Ciriacy M: Xylose fermentation by Saccharomyces cerevisiae. Appl Microbiol Biotechnol 1993, 38:776-783.

19. Bruinenberg PM, Debot PH, van Dijken JP, Scheffers WA: The role of redox balances in the anaerobic fermentation of xylose by yeasts. Eur J Appl Microbiol Biotechnol 1983, 18:287-292.

20. Eliasson A, Christensson C, Wahlbom CF, Hahn-Hägerdal B: Anaerobic xylose fermentation by recombinant Saccharomyces cerevisiae carrying $X Y L, X Y L$, and $X K S$ in mineral medium chemostat cultures. Appl Environ Microbiol 2000, 66:3381-3386.

21. Saloheimo A, Rauta J, Stasyk OV, Sibirny AA, Penttila M, Ruohonen L: Xylose transport studies with xylose-utilizing Saccharomyces cerevisiae strains expressing heterologous and homologous permeases. Appl Microbiol Biotechnol 2007, 74:1041-1052.

22. Runquist D, Fonseca C, Radstrom P, Spencer-Martins I, Hahn-Hagerdal B: Expression of the Gxf1 transporter from Candida intermedia improves fermentation performance in recombinant xylose-utilizing Saccharomyces cerevisiae. Appl Microbiol Biotechnol 2009, 82:123-130.

23. Jin YS, Laplaza JM, Jeffries TW: Saccharomyces cerevisiae engineered for xylose metabolism exhibits a respiratory response. Appl Environ Microbiol 2004, 70:6816-6825.

24. Souto-Maior AM, Runquist D, Hahn-Hagerdal B: Crabtree-negative characteristics of recombinant xylose-utilizing Saccharomyces cerevisiae. $J$ Biotechnol 2009, 143:119-123.

25. Jeffries TW, Grigoriev I, Grimwood J, Laplaza JM, Aerts A, Salamov A, Schumtz J, Linquist E, Dehal P, Shapiro H, Jin YS, Passoth V, Richardson PM: Genome sequence of the lignocellulose-bioconverting and xylosefermenting yeast Pichia stipitis. Nat Biotechnol 2007, 25(3):319-326.

26. Patil KR, Akesson M, Nielsen J: Use of genome-scale microbial models for metabolic engineering. Curr Opin Biotechnol 2004, 15:64-69.

27. Jamshidi N, Palsson BO: Formulating genome-scale kinetic models in the post-genome era. Mol Syst Biol 2008, 4:171.

28. Oberhardt MA, Palsson BO, Papin JA: Applications of genome-scale metabolic reconstructions. Mol Syst Biol 2009, 5:320

29. Park JM, Kim TY, Lee SY: Constraints-based genome-scale metabolic simulation for systems metabolic engineering. Biotechnol Adv 2009, 27(6):979-988.

30. Liu L, Agren R, Bordel S, Nielsen J: Use of genome-scale metabolic models for understanding microbial physiology. FEBS Lett 2010, 584(12):2556-2564

31. Balagurunathan B, Jonnalagadda S, Lee DY, Srinivasan R: Reconstruction of genome scale metabolic model for naturally xylose fermenting yeast Pichia stipitis [abstract]. J Biotechnol 2008, 136S:S49.

32. Thiele I, Palsson BO: A protocol for generating a high-quality genomescale metabolic reconstruction. Nat Protoc 2010, 5(1):93-121.

33. Forster J, Famili I, Fu P, Palsson BO, Nielsen J: Genome scale reconstruction of the Saccharomyces cerevisiae metabolic network. Genome Res 2003, 13:244-253.

34. Bochner BR, Gadzinski P, Panomitros E: Phenotype microarrays for highthroughput phenotypic testing and assay of gene function. Genome Res 2001, 11:1246-1255.

35. Tran AV, Chambers RP: Red oak wood derived inhibitors in the ethanol fermentation of xylose by Pichia stipitis CBS 5776. Biotechnol Lett 1985, 7(11):841-846

36. Tran AV, Chambers RP: Ethanol fermentation of red oak acid prehydrolysate by the yeast Pichia stipitis CBS 5776. Enzyme Microb Technol 1986, 8:439-444.

37. Hunkova Z, Fencl Z: Toxic effects of fatty acids on yeast cells: dependence of inhibitory effects on fatty acid concentration. Biotechnol Bioeng 1977, 19:1623-1641.

38. Kurtzman CP, Fell JW: The Yeasts: A Taxonomic Study. 4 edition. Amsterdam: Elsevier; 1998.

39. Barnett JA, Payne RW, Yarrow D: Yeasts: Characteristics and Identification. 3 edition. Cambridge: Cambridge University Press; 2000.

40. Kanehisa M, Goto S: KEGG: Kyoto Encyclopedia of Genes and Genomes. Nucleic Acids Res 2000, 28:27-30.

41. Jeffries TW: Engineering yeasts for xylose metabolism. Curr Opin Biotechnol 2006, 17:320-326.

42. Hahn-Hagerdal B, Karhumaa K, Jeppsson M, Gorwa-Grauslund MF: Metabolic engineering for pentose utilization in Saccharomyces cerevisiae. Adv Biochem Eng Biotechnol 2007, 108:147-177.
43. Verduyn C, van Kleef R, Frank J, Schreuder H, van Dijken JP, Scheffers WA: Properties of the NAD $(\mathrm{P}) \mathrm{H}$-dependent xylose reductase from xylosefermenting yeast Pichia stipitis. Biochem J 1985, 226:669-677.

44. Skoog K, Hahn-Hagerdahl B: Effect of oxygenation on xylose fermentation by Pichia stipitis. Appl Environ Microbiol 1990, 56(11):3389-3394.

45. Agbogbo FK, Coward-Kelly G, Torry-Smith N, Wenger K, Jeffries TW: The effect of initial cell concentration on xylose fermentation by Pichia stipitis. Appl Biochem Biotechnol 2007, 136-140:653-662.

46. Puchalka J, Oberhardt JA, Godinho M, Bielecka A, Regenhardt D, Timmis KN, Papin JA, Martins dos Santos VAP: Genome-scale reconstruction and analysis of the Pseudomonas putida KT2440 metabolic network facilitates applications in biotechnology. Plos Comput Biol 2008, 4(10):e1000210.

47. Fiaux J, Cakar ZP, Sonderegger M, Wuthrich K, Szyperski T, Sauer U: Metabolic-flux profiling of the yeasts Saccharomyces cerevisiae and Pichia stipitis. Eukaryot cell 2003, 2(1):170-180.

48. Aguilera A: Deletion of the phosphoglucose isomerase structural gene makes growth and sporulation glucose dependent in Saccharomyces cerevisiae. Mol Gen Genet 1986, 204:310-316.

49. Boles E, Lehnert W, Zimmermann FK: The role of the NAD-dependent glutamate dehydrogenase in restoring growth on glucose of a Saccharomyces cerevisiae phosphoglucose isomerase mutant. Eur J Biochem 1993, 217:469-477.

50. Overkamp KM, Bakker BM, Steensma HY, van Dijken JP, Pronk JT: Two mechanisms for the oxidation of cytosolic NADPH by Kluyveromyces lactis mitochondria. Yeast 2002, 19:813-824.

51. Tarrio N, Becerra M, Cerdan ME, Gonzalez Siso MI: Reoxidation of cytosolic NAPDH in Kluyveromyces lactis. FEMS Yeast Res 2006, 6:371-380

52. Sauer W, Canonaco F, Heri S, Perrenoud A, Fischer E: The soluble and membrane bound transdehydrogenase UdhA and PntAB have divergent functions in NAPDH Metabolism of Escherichia coli. J Biol Chem 2004, 279(8):6613-6619.

53. Jeffries TW: Engineering the Pichia stipitis genome for fermentation of hemicelluloses hydrolysates. In Bioenergy. Edited by: Wall JD, Harwood CS, Demain A. Washington: ASM press; 2008:37-47.

54. Joseph-Horne T, Hollomon DW, Wood PM: Fungal respiration: a fusion of standard and alternative components. Biochim Biophys Acta 2001, 1504:179-195.

55. Lighthelm ME, Prior BA, du Preez JC: The effect of respiratory inhibitors on the fermentative ability of Pichia stipitis, Pachysolen tannopilus and Saccharomyces cerevisiae under various conditions of aerobiosis. Appl Microbiol Biotechnol 1988, 29:67-71.

56. Jeppsson H, Alexander NJ, Hahn-Hagerdahl B: Existence of cyanideinsensitive respiration in the yeast Pichia stipitis and its possible influence on product formation during xylose utilization. Appl Environ Microbiol 1995, 61(7):2596-2600.

57. Shi NQ, Davis B, Sherman B, Cruz J, Jeffries TW: Disruption of the Cytochrome c Gene in xylose utilizing yeast Pichia stipitis leads to higher ethanol production. Yeast 1999, 15:1021-1030.

58. Shi NQ, Cruz J, Sherman B, Jeffries TW: SHAM-sensitive alternative respiration in the xylose-metabolizing yeast Pichia stipitis. Yeast 2002, 19:1203-1220.

59. Wittig I, Carrozzo R, Santorelli FM, Schagger H: Supercomplexes and supcomplexes of mitochondrial oxidative phosphorylation. Biochim Biophys Acta 2006, 1757:1066-1072.

60. Boekema EJ, Braun HP: Supramolecular structure of the mitochondrial oxidative phosphorylation system. J Biol Chem 2007, 282:1-4.

61. Heinemeyer J, Braun HP, Boekema EJ, Kouil R: A structural model of the cytochrome $\mathrm{c}$ reductase/oxidase supercomplex from yeast mitochondria. J Biol Chem 2007, 282:12240-12248.

62. Guerrero-Castillo S, Vazquez-Acevedo M, Gonzalez-Halphen D, UribeCarvajal S: In Yarrowia lipolytica mitochondria, the alternative NADH dehydrogenase interacts specifically with the cytochrome complexes of the classic respiratory pathway. Biochim Biophys Acta 2009, 1787:75-85.

63. Oh YK, Palsson BO, Park SM, Schilling CH, Mahadevan R: Genome scale reconstruction of metabolic network in Bacillus subtilis based on highthroughput phenotyping and gene essentiality data. J Biol Chem 2007, 282:28791-28799.

64. Suthers PF, Dasika MS, Kumar VS, Denisov G, Glass JI, Maranas CD: A Genome-scale metabolic reconstruction of Mycoplasma genitalium iPS189. Plos Comput Biol 2009, 5(2):e1000285. 
65. Chung BK, Selvarasu S, Andrea C, Ryu J, Lee H, Ahn J, Lee H, Lee DY: Genome-scale metabolic reconstruction and in silico analysis of methylotrophic yeast Pichia pastoris for strain improvement. Microb Cell Fact 2010, 9:50.

66. Sohn SB, Kim TY, Park JM, Lee SY: In silico genome-scale metabolic analysis of Pseudomonas putida KT2440 for polyhydroxyalkanoate synthesis, degradation of aromatics and anaerobic survival. Biotechnol $J$ 2010, 5(7):739-750.

67. Nigam JN: Ethanol production from wheat straw hemicellulose hydrolysate by Pichia stipitis. J Biotechnol 2001, 87:17-27.

68. Kim JH, Block DE, Mills DA: Simultaneous consumption of pentose and hexose sugars: an optimal microbial phenotype for efficient fermentation of lignocellulose biomass. Appl Microbiol Biotechnol 2010, 88:1077-1085

69. Kanehisa M, Goto S, Hattori M, Aoki-Kinoshita KF, Itoh M, Kawashima S, Katayama T, Araki M, Hirakawa M: From genomics to chemical genomics: new developments in KEGG. Nucleic Acids Res 2006, 34:D354-D357.

70. Aoki-Kinoshita KF, Kanehisa M: Gene annotation and pathway mapping in KEGG. Methods Mol Biol 2007, 396:71-91.

71. Caspi R, Altman T, Dale JM, Dreher K, Fulcher CA, Gilham F, Kaipa P, Karthikeyan AS, Kothari A, Krummenacker M, Latendresse M, Mueller LA, Paley S, Popescu L, Pujar A, Shearer A, Zhang P, Karp PD: The MetaCyc Database of metabolic pathways and enzymes and the BioCyc collection of Pathway/Genome Databases. Nucleic Acids Res 2010, 38(1):D473-D479.

72. Lu Z, Szafron D, Greiner R, Lu P, Wishart DS, Poulin B, Anvik J, Macdonell C, Eisner R: Predicting subcellular localization of proteins using machinelearned classifiers. Bioinformatics 2004, 20:547-556.

73. Claros MG, Vincens P: Computational method to predict mitochondrially imported proteins and their targeting sequences. Eur J Biochem 1996, 241:779-786.

74. Feist AM, Henry CS, Reed $J$, Krummenacker M, Joyce AR, Karp PD, Broadbelt L, Hatzimanikatis V, Palsson BO: A genome-scale metabolic reconstruction for Escherichia coli K-12 MG1655 that accounts for 1260 ORFs and thermodynamic information. Mol Syst Biol 2007, 3:121.

75. Schellenberger J, Park JO, Conrad TC, Palsson BO: BiGG: a Biochemical Genetic and Genomic knowledgebase of large scale metabolic reconstructions. BMC Bioinformatics 2010, 11:213.

76. Cvijovic M, Olivares-Hernández R, Agren R, Dahr N, Vongsangnak W, Nookaew I, Patil KR, Nielsen J: BioMet Toolbox: genome-wide analysis of metabolism. Nucleic Acids Res 2010, 38:W144-W149.

77. Schomburg I, Hofmann O, Baensch C, Chang A, Schomburg D: Enzyme data and metabolic information: BRENDA, a resource for research in biology, biochemistry, and medicine. Gene Funct Dis 2000, 3-4:109-118.

78. Schomburg I, Chang A, Hofmann O, Ebeling C, Ehrentreich F, Schomburg D: BRENDA: a resource for enzyme data and metabolic information. Trends Biochem Sci 2002, 27(1):54-56.

79. Li H, Benedito VA, Udvardi MK, Zhao PX: TransportTP: a two-phase classification approach for membrane transport prediction and characterization. BMC Bioinformatics 2009, 10:418.

80. Francois JM: A simple method for quantitative determination of polysaccharides in fungal cell walls. Nat Protoc 2007, 1(6):2995-3000.

81. Smolders GJ, van der Meij J, van Loosdrecht MC, Heijnen JJ: Stoichiometric model of the aerobic metabolism of the biological phosphorus removal process. Biotechnol Bioeng 1994, 44(7):837-848.

82. Bible KC, Boerner SA, Kaufmann SH: A one-step method for protein estimation in biological samples: nitration of tyrosine in nitric acid. Anal Biochem 1999, 267:217-221.

83. Horwitz W: Official methods of analysis of the AOAC International, 2nd rev. 17 edition. Gaithersburg (MD): AOAC International; 2003.

84. Almog R, Shirey TL: A modified Orcinol test for the specific determination of RNA. Anal Biochem 1978, 91(1):130-137.

85. Matyash V, Leibisch G, Kurzchalia TV, Shevchenko A, Schwudke D: Lipid extraction by methyl-tert-butyl ether for high-throughput lipidomics. J Lipid Res 2008, 49(5):1137-1146.

86. Skipski VP, Peterson RF, Barclay M: Separation of phosphatidylethanolamine, phosphatidylserine and other phospholipids by thin-layer chromatography. J Lipid Res 1962, 3:467-470.

87. Low KL, Rao PS, Shui G, Bendt AK, Pethe K, Dick T, Wenk MR: Triacylglycerol utilization is required for regrowth of in vitro hypoxic nonreplicating Mycobacterium bovis Bacillus calmette-Guerin. J Bacteriol 2009, 191(16):5037-5043.
88. van Urk H, Voll WSL, Scheffers WA, van Dijken JP: Transient-state analysis of metabolic fluxes in crabtree-positive and crabtree-negative yeasts. Appl Microbiol Biotechnol 1990, 56(1):281-287.

89. Becker SA, Feist AM, Mo ML, Hannum G, Palsson BO, Herrgard MJ: Quantitative prediction of cellular metabolism with constraint-based models: The COBRA Toolbox. Nat Protoc 2007, 2:727-738.

90. Schellenberger J, Que R, Fleming RMT, Thiele I, Orth JD, Feist AM, Zielinski DC, Bordbar A, Lewis NE, Rahmanian S, Kang J, Hyduke DR, Palsson BO: Quantitative prediction of cellular metabolism with constraint-based models: the COBRA Toolbox v2.0. Nat Protoc 2011, 6(9):1290-307.

doi:10.1186/1475-2859-11-27

Cite this article as: Balagurunathan et al:: Reconstruction and analysis of a genome-scale metabolic model for Scheffersomyces stipitis. Microbial Cell Factories 2012 11:27.

\section{Submit your next manuscript to BioMed Central and take full advantage of:}

- Convenient online submission

- Thorough peer review

- No space constraints or color figure charges

- Immediate publication on acceptance

- Inclusion in PubMed, CAS, Scopus and Google Scholar

- Research which is freely available for redistribution

Submit your manuscript at www.biomedcentral.com/submit
Biomed Central 